\title{
PROGRESS REPORT ON CYCLIC LOAD TESTS ON PRESTRESSED PARTIALLY PRESTRESSED AND REINFORCED CONCRETE INTERIOR BEAM-COLUMN ASSEMBLIES
}

\author{
R. Park" and K. J. Thompson**
}

\section{INTRODUCTION}

The University of Canterbury is at present conducting an experimental investigation into the seismic resistance of concrete building frames. This research project is sponsored by the N.Z. Prestressed Concrete Institute, the Building Research Association (NZ) and the University. The test frames include a range of proportions of prestressing steel and ordinary reinforcing steel to allow a comparison of prestressed and reinforced concrete frames and to establish the possible advantages of combining both systems. The tests are aimed at determining the deformation capacity and degree of damage of such frames when responding to severe seismic load reversals and will establish further basic information for the evaluation and design of framed structures for earthquake resistance.

The specimens consist of beam-column assemblies with either a prestressed, partially prestressed or reinforced concrete beam. This paper summarizes the results obtained from the first eight test units. The results from the first seven units may he seen reported in more detail elsewhere

\section{DETAILS OF TEST SPECIMENS AND LOADING}

\subsection{Overall Dimensions and Loading}

The beam-column test unit represented the part of the building frame shown encircled in Fig. 1. The unit can be regarded as being the part of the frame between the points of contraflexure at a typical interior joint. The unit was loaded as shown in Fig. 2 by an axial load $P$ on the column representing load due to the weight of the building, floor loads, and overturning moment, and by vertical loads on the ends of the beams representing shear induced by earthquake loading. The applied beam loads induce reactive shears at the ends of the column. By reversing the direction of the vertical loads the effects of earthquake shaking was simulated. The vertical loading was such as to enforce deformations into the inelastic range several times following a loading cycle representing the action of a major earthquake. The cyclic loading was applied slowly over a time period of days rather than rapidly over a time period of seconds as would occur in an actual earthquake. However, it is considered that the results obtained from the slow load reversals of

* Professor of Civil Engineering, University of Canterbury.

* Graduate Student, University of Canterbury. the tests give a conservative indication of the response of a concrete frame to actual earthquake shaking.

Fig. 3 shows the overall dimensions of the test units. The cross-sections can be considered to be representative of fullsize members of frames with small number of storeys, or to be smaller than full-size. Both the beam and the column are continuous through the joint. The steel content is such that the column section is stronger than the beam so that under very severe seismic loading plastic hinging is enforced in the beam rather than in the column. Thus the critical sections are in the beam adjacent to the column faces.

Fig. 4 shows a unit set up in the test frame at the start of testing.

\subsection{Steel and Concrete Details}

Fig. 5 shows the steel in the joint region of a unit before the concrete was placed. The column and beam sections of the eight test units are shown in Figs. 6 and 7 .

All beams had an 18 in deep $x 9$ in wide cruss-section. The beams contained various quantities of prestressed and nonprestressed steel and were designed to have approximately the same flexural strength. The prestressing tendons were post-tensioned to approximately $70 \%$ of the ultimate tensile strength and grouted. The nonprestresed steel was from mild steel deformed bar. Details of the longitudinal beam steel were as follows:

Unit 1 Prestressed 3 - 12/0.2" dia. tendons beam 4 - No. 3 mild steel deformed bars

Unit 2 Partially 1 - 12/0.2" dia. tendon prestressed 4 - No. 9 mild steel beam deformed bars

Unit 3 Reinforced 4 - No. 9 and 2 - No. 8 beam mild steel deformed bars

Unit 4 Prestressed $3-12 / 0.2 "$ dia. tendons beam 4 - No. 3 mild steel deformed bars

Unit 5 Prestressed 2 - 10/0.276" dia. tendons beam 4 - No. 3 mild steel deformed bars

Unit 6 Partially 1 - 12/0.2" dia. tendon prestressed 8 - No. 6 and 2 - No. 4 beam mild steel deformed bars

Unit 7 Partially $3-4 / 0.276 "$ dia. tendons prestressed 4 - No. 6 mild steel beam

Unit 8 Prestressed $3-12 / 0.2^{\text {" dia. tendons }}$ beam 4 - No. 3 mild steel deformed bars 
The beam stirrups were from No. 3 plain round mild steel bar placed at 7 in centres in Unit 1 and at 3.5 in centres in all other units. The cover to the stirrups was 1.5 in for Units 1 to 7 and 0.375 in for Unit 8 . The stirrups were capable of carrying all of the beam shear force by truss action.

The columns of the units were identical. Each column had a 16 in $x 12$ in section and contained four No. 7 HY 60 deformed steel bars. The ties were from No. 3 plain round mild steel bar placed at 7 in centres. In the columns some shear was assumed to be carried by the concrete. The axial column load during testing was 100 tons.

The joint core was reinforced for shear by rectangular hoops formed from No. 5 plain round mild steel bar placed at 2 in centres. The hoops were to carry the horizontal shear force acting on the joint core due to the column shear and the tensile and compressive forces in the beams acting each side of the joint core. Some joint shear was assumed to be carried by the concrete.

The Appendix gives the details of the steel and concrete properties of the units.

\section{3 prestress and Theoretical Member Strengths}

The prestress in the beams and the theoretical strengths of the members calculated using the actual strength of the materials are shown in Table 1 . The theoretical flexural strengths were found by satisfying force equilibrium and strain compatibility at an extreme fibre compressive concrete strain of 0.003 ; the actual stressstrain curve for the steel was used and for concrete the compressive stress distribution given by $A C I$ 318-71(2) was assumed. The shear strengths were calculated using the equations from ACI 318-71. The capacity reduction factor $\phi$ was assumed to be unity in all strength calculations. Further details of theoretical strength calculations are given in the Appendix.

\section{DETAILS OF TESTS}

The test units were subjected to a series of very severe earthquake type load cycles as previously described which caused deformations well into the inelastic range. The specimens were loaded by enforcing vertical deflections at the ends of the beams (see Fig. 2). During the loading cycles an axial load of 100 tons was applied to the ends of the columns and the column ends were held against lateral displacement. During the loading, the initial cycles were in the elastic range and then the amplitude of beam end deflection was increased. At least three loading runs in each direction to a beam end deflection of $3-5$ in were applied to each specimen. It is to be noted that it was calculated theoretically that when yielding of the steel of the reinforcing concrete beam commenced the beam end deflection would be 1.1 in, assuming fully cracked beams and columns. Thus, theoretically, a beam end deflection of approximately 4.4 in was required to enforce a displacement ductility factor of four.

During the loading cycles the deflections at the ends of beams and elsewhere were measured by dial gauges and rules. Strains were measured on the surface of the concrete by Demec gauges and on some of the reinforcement by Demec gauges or electrical resistance strain gauges. Rotations were measured at the plastic hinge positions in the beams by dial gauges attached to frameworks around the beams at 4 in and 12 in out from the column faces, or by strains on the reinforcement measured by Demec gauges.

The damaged concrete of one unit (Unit 1) was repaired after testing to see if satisfactory structural behaviour could be achieved. The repair was carried out by jacking the damaged beams back to the horizontal position, chipping away the damaged concrete in the plastic hinge regions of the beams, placing two No. 3 stirrups around the remaining core of the beams in each damaged region, and replacing the removed concrete by new concrete to give the original cross-sectional dimensions. After a time interval for curing and gaining strength the repaired test unit was subjected to cyclic loading. Only Unit 1 was repaired and retested.

\section{LOAD-DEFORMATION AND STRENGTH BEHAVIOUR}

Figs. $8 a-16 a$ show for each unit the vertical deflection at the end of the left beam plotted against the beam moment at the column face. Fig. $8 b-16 b$ show for each unit a plot of the moment-curvature characteristic measured over a gauge length in the plastic hinge zone adjacent to the column face in the left beam. The numbers of the curves correspond to the peaks of the loading runs. In loading runs 1 to 4 the deformations were within the elastic uncracked or cracked range of the beams.

The moment-deflection and momentcurvature loops indicate the degree of strength and stiffness degradation occurring during the cyclic loading. Table 2 lists the ratio of the maximum experimental bending moment reached at the left hand beam face in each direction to the theoretical ultimate moment (shown in Table 1 ).

Comparison of the moment-deflection and moment-plastic hinge curvature loops for each unit gives a good indication of where the inelastic deformation was concentrated. For example, Figs. $8 \mathrm{a}$ and $8 \mathrm{~b}$ are of a similar shape, indicating that the major inelastic contribution to end deflection came from the deformation at the plastic hinge in the beam close to the column face. Similarly for Units 4 and 7 . In these three units (Units 1,4 and 7), the joint core region remained intact. In the remaining Units, the beam plastic hinge rotation became smaller as the load cycles proceeded because the inelastic deformation concentrated in the joint core (see Figs. $10 \mathrm{~b}, 11 \mathrm{~b}, 13 \mathrm{~b}, 14 \mathrm{~b}$, and 16b). This softening of the joint core was due to intense diagonal tension cracking there leading to large shear deformations in the deteriorated joint core and, in some units, to slip of the beam steel through the joint core.

In the prestressed beams of Units 1 and 4 the reduction of moment capacity and 
stiffness was due to crushing of the cover concrete outside the stirrups resulting in a reduction in the concrete cross-section. The reduction in moment capacity of Unit 7 was not so large due to the presence of compression steel which maintained good load carrying capacity after crushing of concrete occurred. The remaining units (Units 2, 3, 5,6 and 8) showed a reduction in strength after the initial inelastic load cycle due to the reduction in shear strength of the joint core.

\section{DISCUSSION}

\subsection{Units With Fully Prestressed Beams (Units}

The beams of Units $1,4,5$ and 8 had a concrete prestress at transfer of 1160,1123 , 1198 and 1146 psi respectively, and nominal longitudinal mild steel. The differences were in the number of tendons (three with one at mid depth in the case of Units 1,4 and 8. two without one at mid depth in the case of Unit 5), in the beam stirrup spacing ( 7 in in the case of Unit $1,3.5$ in in the case of Units 4,5 and 8 ), and in the concrete cover to the beam stirrups $(1.5$ in in the case of Units 1,4 and 5 , and 0.375 in in the case of Unit 8).

These four units showed an ability to be loaded to near maximum moment capacity and then to be unloaded with negligible residual damage. The maximum measured moment capacities reached in the beams exceeded the theoretical flexural strength by $7-16 \%$ and $3-14 \%$ in the initial elastic loading runs in each direction. This overstrength was mainly due to the extra confinement given to the beam concrete by the adjacent concrete column which delayed crushing of the concrete at the maximum moment section until an extreme fibre concrete strain much greater than 0.003 was reached. The moment capacity of the sections increased at these higher strain levels because they were accompanied by greater stresses in the prestressing tendons. Subsequent to the commencement of crushing of the compressed concrete the energy dissipation capacity was large.

Degradation of stiffness and strength occurred after crushing of the concrete had commenced, mainly because of the reduction in cross sectional area of the beams. Comparison of the load-deflection curves of Units 1 and 4 (Figs. $8 a$ and $12 a$ ) shows the effect of 7 in and 3.5 in stirrup spacing in the beams. The closer stirrup spacing did not have a marked influence on the ductility of the beam because the closer spacing did not present loss of the cover concrete and hence did not prevent loss of stiffness and strength due to crushing of the cover concrete. However, a close comparison of the loaddeflection curves of Figs. $8 \mathrm{a}$ and $12 \mathrm{a}$ shows the beneficial effect of the closer stirrup spacing. The load was still increasing at the end of loading runs 7 to 12 of Fig. 12a, whereas in Fig. $8 \mathrm{a}$ the load is not increasing so markedly at the end of these loading runs due to the deeper penetration of concrete crushing into the beam core. The 3.5 in spacing was approximately $d / 4$, if the effective depth $d$ is taken to be 0.8 of the overall depth of the member. On this basis, spacing of closed stirrups in plastic hinge zones of not greater than $d / 4$, or 4 in, could be encouraged because of the better confinement of the concrete core. Also, closer stirrup spacing will result in more effective shear resistance when the concrete mechanisms of shear transfer deteriorate during inelastic loading cycles. This recommended maximum stirrup spacing is similar to that of ACI 318-71 (2) for reinforced concrete. Comparison of the load-deflection curves of Units 4 and 8 (Figs. 12a and 16a) shows the effect of 1.5 in and 0.375 in cover to the stirrups. It is evident that the reduction in moment capacity when concrete crushing commenced (loading runs 5 and 6 ) was less significant in the member with the smaller cover due to the larger confined core. Thus to obtain the flexural strength of members at a high level after concrete crushing the cover thickness should be kept as small as possible.

The shear reinforcement provided in the beams and columns of the four test units resulted in satisfactory shear resistance of those members. The shear reinforcement provided in the joint cores resulted in satisfactory shear resistance for Units 1 and 4 but not for Units 5 and 8 . In the central region of the joint core the horizontal shear force (beam internal forces minus column shear force) was 212 , 221,249 and 216 kips for Units 1, 4, 5 and 8 , respectively, at the theoretical flexural strength of the beams. The theoretical shear strength of the joint cores according to the approach of ACI 318-71 for reinforced concrete (see Table 1 and the Appendix) was 217, 219, 219 and 218 kips for Units $1,4,5$ and 8 respectively. (It is to be noted that the maximum shears acting on the joint cores during the tests would have exceeded these theoretical values calculated from the beam and column forces at the theoretical flexural strengths by approximately the order of strength increase indicated in Table 2). Units 1 and 4 which did not fail in joint shear, were theoretically within $2 \%$ of the ACI strength. Unit 5 which failed in joint shear was theoretically $12 \%$ understrength according to the ACI approach. The higher horizontal shear acting on the joint core of Unit 5 may have led to its failure. Also, a central prestressing tendon was absent from Unit 5. The central prestressing tendon in Units 1 and 4 probably assisted in controlling the width and development of the diagonal tension cracks and in maintaining the shear resistance of the joint core. This would be so because of the residual prestress in the central tendon, even after large deformations of the beam, and because the tendon crossed the cracks. However, Unit 8 which had a central tendon failed eventually in joint shear. The main difference between Unit 8 and Unit 4 was that the smaller concrete cover of Unit 8 enabled the beam to maintain its moment carrying capacity better during the cyclic loading which meant that the shears on the joint core were held at a high level for a greater part of the loading runs. Also, in Unit 8 , because of the greater depth of concrete core, the neutral axis was further away from the central tendon than in the case of Units 1 and 4 . This meant that the central tendon in Unit 8 was 
plastically strained in the major load cycles (whereas in Units 1 and 4 the central tendon remained in the elastic range) leading to less effective control of joint core cracking. It is apparent that the ACI approach for shear design of joint cores may not be adequate in the general case. In the general case it would seem to be safer to disregard the contribution of the concrete shear resisting mechanism in the joint and to carry all the joint shear on the shear reinforcement (see the further discussion in the Appendix).

The end deflection-beam moment curves of Units 4 and 5 are very similar (Figs. $12 \mathrm{a}$ and 13a) in spite of the fact that in Unit 4 failure concentrated at the beam plastic hinges and in Unit 5 failure concentrated in the joint core. However, inelastic joint core deformation must be regarded as undesirable because of the difficulty of subsequent repair of joint cores and the possible collapse of the building due to loss of load carrying capacity of columns. Therefore plastic hinging in beams is more desirable.

The repair of Unit $I$ by straightening the damaged beams, removing the damaged concrete in the plastic hinge region and replacing the concrete there, demonstrated that it is possible to repair prestressed concrete members. The two extra stirrups placed within the new concrete at each repaired plastic hinge region helped confine the concrete there and the performance of the repaired unit in the subsequent load testing was satisfactory. It is emphasized that the new concrete was not prestressed. The prestressing tendon there functioned merely as ordinary reinforcement. However, the general performance of the repaired unit was satisfactory although as expected the crack control in the new concrete was not as good as in the original unit. For instance, at $63 \%$ of the experimental ultimate moment the maximum crack width in the new concrete was approximately 0.015 in, whereas in the original prestressed beam that crack width was not reached until $98 \%$ of the experimental ultimate moment had been applied.

\subsection{Units With Partially Prestressed Beams (Units 2,6 and 7 )}

The beams of Units 2,6 and 7 had a concrete prestress at transfer of 386,371 and 675 psi, respectively. The beams of Units 2 and 6 had a single central prestressing tendon and Unit 7 had three tendons (one at top, one at midspan, and one at bottom). The non prestressed steel of Unit 2 consisted of 4 - No. 9 bars, whereas for Unit 6 it was 8 - No. 6 and 2 - No. 4 and for Unit 7 it was 4 - No. 6 bars. All other details were the same for these three units. Thus the main variables were the amount of prestress and amount and size of nonprestressed steel.

These three units showedan ability to be loaded to near their maximum moment capacity and then to be unloaded with very little residual damage. The maximum measured moment capacities reached in the beams exceeded the theoretical flexural strength by $2-6 \%$ and $3-98$ in the initial inelastic loading runs in each direction. Energy dissipation subsequent to the maximum moments being reached in each direction was large.

In the case of Units 2 and 6 , after the maximum moment had been reached in each direction, there was with further loading cycles a deterioration of the concrete in the joint core caused by repeated opening and closing of diagonal tension cracks in alternating directions and the yielding of the hoop steel. This deterioration of the joint core caused a reduction in the strength and stiffness of the unit. Thus for these two units the damage concentrated in the joint core rather than in the beams, and it was evident that the shear reinforcement in the joint core was inadequate. The use of smaller diameter nonprestressed beam bars in Unit 6 than in Unit 2 did reduce the deterioration of the bond between the concrete and the beam bars through the joint core. In Unit 2 the beam bars slipped backwards and forwards through the joint core from loading run 7 onwards whereas in Unit 6 no significant slip occurred. The smaller bars of Unit 6 did not prevent a deterioration of the joint core strength however. In the central region of the joint core the horizontal shear force was 214 and 218 kips for Units 2 and 6 , respectively, at the theoretical flexural strength of the beams. The theoretical shear strength of the joint core according to the approach of ACI 318-71 (see Table 1 and the Appendix) was 220 kips for both units. Hence for both of these units joint core shear failure was imminent according to the ACI procedure, and indeed occurred.

In the case of Unit 7 the joint core remained intact and the inelastic deformations concentrated in the plastic hinges of the beams. This unit was better able to maintain its strength with further load cycles, and showed fairly stable loaddeflection loops, thus indicating the value of a higher level of prestress in the beam.

\subsection{Unit with Ordinary Reinforced Beam (Unit 3)}

Unit 3 had $2 \%$ of nonprestressed mild steel in both the top and the bottom of the beam.

Unit 3 was capable of being loaded to near maximum moment capacity and then unloaded with little residual damage. The maximum measured moment capacities reached in the beams were $3 \%$ greater and 5\% smaller than the theoretical flexural strength in the initial inelastic loading runs in each direction. The energy dissipation was large subsequent to the maximum moments being reached. During the load cycles subsequent to the maximum moments being reached there was a deterioration in the joint core concrete due to repeated diagonal tension cracking and yielding of hoop steel. This caused a reduction in the strength and stiffness of the unit and damage concentrated in the joint core rather than in the beams.

The shear reinforcement in the joint core was inadequate to prevent shear failure. In the central region of the joint core the horizontal shear force was 
$207 \mathrm{kips}$ at the theoretical flexural strength of the beams, and the theoretical shear strength of the joint core was $220 \mathrm{kips}$ (see Table 1 and the Appendix). Hence in this case the ACI design procedure for the joint core was inadequate.

\subsection{Further Test Units}

To complete the series two further test units will be tested before the end of January, 1975. These are as follows:

Unit 9 : Similar to Unit 5 (fully prestressed beam with two tendons, one in the top and one in the bottom) but with more joint core shear reinforcement. This will check whether the joint core shear failure of Unit 5 (no central tendon but 1200 psi prestress at transfer) can be avoided by carrying all of the horizontal shear force on the hoops.

Unit 10 : Similar to Unit 6 (partially prestressed beam with one central tendon) but with more joint core shear reinforcement. This will check whether the joint core shear failure of Unit 6 (one central tendon but only 370 psi prestress at transfer) can be avoided by carrying all of the horizontal joint shear force on the hoops.

Further test units have been suggested for a new test programme involving the following variables:

\section{Unsymmetrical arrangements and} different amounts of prestressed and nonprestressed steel in the beam sections. For example, prestress with an upward eccentricity, more nonprestressed steel in the top of the section than in the bottom, and smaller steel quantities leading to smaller neutral axis depths.

2. Other axial load levels on the column. Change of column axial load level will affect the bond strength of beam bars and the diagonal tension cracking in the joint core.

3. Other means of increasing the shear strength of the joint core, for example by better anchorage of the beam bars (e.g. by welded anchorage devices), crossover beam bars through the joint core, or the use of a greater number of column bars to provide vertical reinforcement across the joint core at the perimeter of the column. The use of fibre reinforced concrete in the joint core is a promising alternative, the fibres increasing the tensile strength and ductility of the concrete.

4. Other spans of beams to obtain different bending moment/shear force ratios at the beam plastic hinges.

5. Unbonded post-tensioned tendons. Such tendons remain elastic during the whole loading range and hence prestress across the joint is maintained even after severe seismic type loading.

\section{CONCLUSIONS}

The results of the first eight test units have enabled some comparison to be made of the behaviour of full-scale prestressed, partially prestressed and ordinary reinforced concrete beam-column assemblies subjected to intense seismic loading. Full conclusions must await the completion of the test series. The tentative conclusions from the tests already conducted are:

1. Beams: The prestressed beams showed a reduction in strength and stiffness, once concrete crushing occurred, due to loss of the cover concrete causing a reduction in the area of the section in the plastic hinge region. Transverse steel in the form of closed stirrups with minimum concrete cover should be used in such zones to prevent excessive loss of the concrete section. Transverse steel will not prevent the loss of the cover concrete but closely spaced closed stirrups will prevent crushing penetrating deep into the concrete core. It appears that the stirrup spacing should not exceed 4 in or one quarter of the effective depth of the member. The partially prestressed and ordinary reinforced beams were not so influenced by concrete crushing mainly because of the presence of compression reinforcement. However, compression reinforcement may slip through the joint core due to breakdown of bond, particularly if the column section is small and the bar diameter is large, thus reducing its effectiveness.

The flexural strength of the beams in the first inelastic loading runs was 2-16\% higher than the theoretical flexural strength, due mainly to the maximum moment being reached at an extreme fibre compressive concrete strain of greater than 0.003 and due to confinement of the compressed beam concrete immediately adjacent to the column face by the column.

2. Columns: In these tests the columns were stronger than the beams and hence were not critical elements, apart from in the joint core regions.

3. Joint Cores: The shear reinforcement of the joint cores had been designed according to the method of ACI 318-71. In this method the horizontal shears induced in the joint core by the beam forces and the column shears are assumed to be carried by a mechanism involving the concrete (aggregate interlock, etc.) and the hoops (truss action), in a similar fashion to shear in structural members. In the case of two units with an initial prestress in the beams of 1100-1200 psi from three tendons (at top, centre and bottom of the section), joint core shear failure did not occur. Also in the case of one unit with a partially prestressed beam with an initial prestress of 675 psi from a single central tendon, joint shear failure did not occur. However, two units with partially prestrssed beams with initial prestress of 370-390 psi from a single central tendon, one unit with a prestressed beam with initial prestress of 1150 psi from three tendons (at top, centre and bottom of section) and small concrete cover which maintained a high moment capacity during the initial loading cycles, one unit with a prestressed beam with initial prestress of 1200 psi from two tendons (at top and bottom of section) and $12 \%$ underdesign for joint shear, and one unit with a reinforced concrete beam, all eventually failed in diagonal tension at the joint core. These units all reached their 
theoretical flexural strength in the first loading run in each direction (except for the reinforced concrete beam which reached 958 of theoretical strength in the reversed load run) accompanied by yielding of the joint core hoops, and in further loading cycles the shear strength of the joint cores degraded. The strength of the joint core then governed the strength of the unit and the greater part of the inelastic deformation of the unit occurred in the joint core. Thus the ACI 318-71 approach for joint core shear design was inadequate in some cases. Note that the ACI method allowed the attainment of the strength satisfactorily in the first cycle of loading. Streng th degradation occurred in the subsequent cycles due apparently to a breakdown in the shear resisting mechanism of the concrete. It is evident that a high level of prestress and a central tendon help joint core shear behaviour. Aspects of joint core behaviour are at present still being analysed and the results of the further tests are awaited. Some additional comments on design procedure are made in the Appendix.

4. Energy Dissipation: All units showed considerable energy dissipation once the maximum moment capacities had been reached. As expected, even after extensive inelastic deformations had been enforced, the prestressed concrete beam showed considerable ability to recover. The ordinary reinforced member showed greater energy dissipation than the partially prestressed member. However, comparisons between these specimens are difficult because the inelastic deformations from some units came mainly from the beam plastic hinges, and in others from the shear deformations of the joint cores.

5. Repair: Repairs made to a prestressed beam by replacing the damaged beam concrete showed that it was possible to repair damaged members. Repairs to units with extensive damage to joint cores would have been much more difficult if not impossible to carry out, however.

\section{ACKNOWLEDGEMENTS}

The tests reported were carried cut in the laboratories of the Department of Civil Engineering, University of Canterbury. The authors are particularly indebted to technicians A. G. Foot, J. M. Adams and G. E. Hill for assistance with the experimental work.

The financial assistance of the following organisations is gratefully acknowledged:

University of Canterbury.

Building Research Association (N.z.).

N.z. Prestressed Concrete Institute, who have received contributions towards the project from: W. R. Grace (N.Z.) Ltd., Golden Bay Cement Co. Ltd., Wilson (N.Z.) Portland Cement Ltd., N.z. Cement Holdings Itd. Cookes NZ Wire Rope Ltd., Australian Wire Industries Pty Ltd (BHP), B \& B Concrete Co. Itd., stresscrete Group, BBR New Zealand Ltd., S. Austin Carr \& Co. Ltd.., NZ Steel/ Pacific Steel, and Mainline-Fletcher.

8. REFERENCES

(1) Park, R. and Thompson, K. J., "Behaviour of Prestressed, Partially Prestressed and Reinforced Concrete Interior Beam - Column Assemblies Under Cyclic Loading : Test Results of Units 1 to 7", Research Report 74-9, Department of Civil Engineering, University of Canterbury, 1974, 42p.

(2) ACI Committee 318, "Building Code Requirements for Reinforced Concrete (ACI 318-71)", American Concrete Institute, Detroit, 1971, pp.78. 
TABLE 1.

PRESTRESS AND THEORETICAL STRENGTHS OF MEMBERS

\begin{tabular}{|c|c|c|c|c|c|c|}
\hline \multirow[t]{2}{*}{ Unit } & \multirow{2}{*}{$\begin{array}{c}\text { Concrete Prestress } \\
\text { in Beam at Transfer, } \\
\text { psi }\end{array}$} & \multicolumn{2}{|c|}{$\begin{array}{c}\text { Flexural strength*, } \\
\text { kip in }\end{array}$} & \multicolumn{3}{|c|}{ Shear strength,+ kips } \\
\hline & & Beam & Column $x$ & Beam & Column & $\begin{array}{l}\text { Joint } \\
\text { core }\end{array}$ \\
\hline 1 & 1160 & 1495 & 2047 & 36.6 & 53.4 & 217 \\
\hline 2 & 386 & 1730 & 2134 & 57.1 & 56.6 & 220 \\
\hline 3 & - & 1672 & 2137 & 61.6 & 56.2 & 220 \\
\hline 4 & 1123 & 1588 & 2077 & 56.3 & 55.0 & 219 \\
\hline 5 & 1198 & 1734 & 2107 & 56.7 & 58.0 & 219 \\
\hline 6 & 371 & 1708 & 2121 & 67.6 & 58.4 & 220 \\
\hline 7 & 675 & 1601 & 2123 & 67.5 & 58.3 & 220 \\
\hline 8 & 1146 & 1571 & 2062 & 59.4 & 56.8 & 218 \\
\hline
\end{tabular}

* Using for concrete the ACI stress block and an extreme fibre compressive strain of 0.003

+ Using ACI 318-71 approach carrying shear on concrete and transverse steel

$\mathrm{x}$ With axial load of 100 tons present.

TABLE 2.

FLEXURAL STRENGTHS OF LEFT HAND BEAM AT COLUMN FACE

\begin{tabular}{|ccc|}
\hline Unit & $\begin{array}{c}\text { Max. Experimental Moment } \\
\text { from Downward Load } \\
\text { Theoretical Ultimate Moment }\end{array}$ & $\begin{array}{c}\text { Max. Experimental Moment } \\
\text { from Upward Load } \\
\text { Theoretical Ultimate Moment }\end{array}$ \\
\hline 1 & 1.09 & 1.03 \\
Repaired 1 & $0.86^{\star}$ & $0.97^{\star}$ \\
2 & 1.04 & 1.08 \\
3 & 1.03 & 0.95 \\
4 & 1.16 & 1.05 \\
6 & 1.07 & 1.08 \\
7 & 1.02 & 1.07 \\
8 & 1.06 & 1.03 \\
\hline
\end{tabular}

* Theoretical ultimate moment used is that of the original section. 
9. APPENDIX

9.1 Steel Properties

Prestressed Steel

\begin{tabular}{ccccc}
\hline Unit & $\begin{array}{c}\text { Diameter } \\
\text { in. }\end{array}$ & $\begin{array}{c}\text { 0.2\% Proof } \\
\text { Stress, ksi }\end{array}$ & $\begin{array}{c}\text { Ultimate Tensile } \\
\text { Strength, ksi }\end{array}$ & $\begin{array}{c}\text { Ultimate Strain } \\
\text { (8" gauge length) }\end{array}$ \\
\hline 1 & 0.2 & 210 & 236 & 5.4 \\
2 & 0.2 & 210 & 236 & 5.4 \\
4 & 0.2 & 207 & 234 & 6.0 \\
5 & 0.276 & 212 & 244 & 5.2 \\
6 & 0.2 & 199 & 236 & 4.6 \\
7 & 0.276 & 206 & 232 & 4.6 \\
8 & 0.2 & 199 & 235 & 5.3 \\
\hline
\end{tabular}

Nonprestressed Longitudinal Steel (Deformed bars) Yield Strength, ksi *

\begin{tabular}{ccccccc}
\hline Unit & No. 7 & No. 9 & No. 8 & No. 6 & No. 4 & No. 3 \\
\hline 1 & 58.8 & & & & 41.1 \\
2 & 59.2 & 41.4 & & & \\
3 & 60.2 & 40.4 & 46.0 & & & \\
4 & 57.6 & & & & 47.1 \\
5 & 58.5 & & & & 42.1 & \\
6 & 59.0 & & 41.5 & & \\
7 & 58.7 & & & & 48.5 \\
8 & 58.4 & & & & & \\
\hline
\end{tabular}

* Based on nominal areas

Transverse Steel (Plain bars) Yield Strength, ksi *

\begin{tabular}{lccc}
\hline Unit & $\begin{array}{c}\text { No. } 5 \text { Joint } \\
\text { Hoops }\end{array}$ & $\begin{array}{c}\text { No. } 3 \text { Beam } \\
\text { Stirrups }\end{array}$ & $\begin{array}{c}\text { No. } 3 \text { Column } \\
\text { Ties }\end{array}$ \\
\hline $1,2,3$ and 4 & 43.5 & 41.9 & 41.9 \\
5,6 and 7 & 43.5 & 47.3 & 47.3 \\
8 & 43.5 & 45.7 & 47.3 \\
\hline
\end{tabular}

* Based on nominal areas 


\subsection{Concrete Properties}

\begin{tabular}{|c|c|c|c|c|c|c|}
\hline Unit & $\begin{array}{l}\frac{\text { Aggregate }}{\text { Cement }}_{\text {ratio, }} \\
\text { by weight }\end{array}$ & $\begin{array}{l}\frac{\text { Water }}{\text { Cement ratio, }} \\
\text { by weight }\end{array}$ & Slump & $\begin{array}{l}\text { Age at } \\
\text { Test, } \\
\text { days }\end{array}$ & $\begin{array}{l}\text { Mean }^{+} \\
\text {Compressive } \\
\text { Cylinder } \\
\text { strength } \\
\quad \text { psi }\end{array}$ & $\begin{array}{l}\text { Mean } \\
\text { Modulus of } \\
\text { Rupture, } \\
\quad \text { psi }\end{array}$ \\
\hline 1 & 6.8 & 0.55 & $4 \frac{1}{4}$ & 76 & 4630 & 837 \\
\hline 2 & 5.95 & 0.53 & $4 \frac{1}{4}$ & 80 & 5510 & 817 \\
\hline 3 & 5.95 & 0.53 & $4 \frac{1}{4}$ & 55 & 5400 & 729 \\
\hline 4 & 5.95 & 0.53 & $4 \frac{1}{4}$ & 66 & 5050 & 846 \\
\hline 5 & 5.4 & 0.45 & $4 \frac{1}{4}$ & 64 & 5240 & 705 \\
\hline 6 & 5.4 & 0.45 & $4 \frac{1}{4}$ & 120 & 5360 & 819 \\
\hline 7 & 5.4 & 0.45 & $4 \frac{1}{4}$ & 93 & 5330 & 749 \\
\hline 8 & 5.4 & 0.45 & $4 \frac{1}{4}$ & 48 & 4810 & 665 \\
\hline
\end{tabular}

* Maximum aggregate size $=3 / 4$ in

+ Air dried after one week of curing with the unit

New Concrete in Repaired Unit 1

Aggregate:cement:water ratio, by weight $=4.6: 1.0: 0.48$. Maximum aggregate size $=3 / 8$ in slump $=3$ in

Age at test $=66$ days. $12 " \times 6 "$ dia. cylinder strength $=7400$ psi.

\subsection{Beam Forces at Theoretical Flexural Strength}

Fig. 17 shows a beam section at the flexural strength. Using the actual stress-strain curves for the steel, and satisfying strain compatibility and equilibrium, the theoretical neutral axis depth, and internal forces for the beams of the units may be found to be:

\begin{tabular}{cccccccccc}
\hline Unit & \multirow{2}{*}{$\begin{array}{c}\mathrm{C} \\
\text { in }\end{array}$} & in & \multicolumn{1}{c}{$\begin{array}{c}\mathrm{T}_{1} \\
\text { kip }\end{array}$} & $\begin{array}{c}\mathrm{T}_{2} \\
\text { kip }\end{array}$ & $\begin{array}{c}\mathrm{T}_{3} \\
\text { kip }\end{array}$ & $\begin{array}{c}\mathrm{T}_{4} \\
\text { kip }\end{array}$ & $\begin{array}{c}\mathrm{C}_{5} \\
\text { kip }\end{array}$ & $\begin{array}{c}\mathrm{C} \\
\text { kip }\end{array}$ & $\begin{array}{c}\mathrm{M}_{\mathrm{u}} \\
\text { kip in }\end{array}$ \\
\hline 1 & 6.43 & 5.27 & 75.3 & 69.2 & 41.9 & 9.0 & 9.0 & 186.4 & 1495 \\
2 & 3.21 & 2.49 & - & 78.8 & - & 82.9 & 56.9 & 104.8 & 1730 \\
3 & 2.78 & 2.17 & - & - & - & 118.2 & 29.0 & 89.2 & 1672 \\
4 & 6.36 & 5.07 & 77.5 & 72.9 & 45.1 & 10.5 & 10.2 & 195.9 & 1588 \\
5 & 6.47 & 5.09 & 129.3 & - & 75.1 & 10.4 & 10.4 & 204.3 & 1734 \\
6 & 3.71 & 2.90 & - & 79.9 & - & 84.2 & 45.3 & 118.8 & 1708 \\
7 & 4.00 & 3.13 & 51.7 & 48.7 & 27.8 & 36.1 & 36.6 & 127.7 & 1601 \\
8 & 6.32 & 5.12 & 76.1 & 69.8 & 42.4 & 10.7 & 10.6 & 188.4 & 1571 \\
\hline
\end{tabular}




\subsection{Shear Strength of Members}

According to ACI $318-71^{2}$

$$
v_{u}=v_{c} b d+A_{s} f_{y} d / s
$$

where $v_{\text {}}=$ shear stress carried by the concrete, $b=$ width of the section, $d=$ distánce from extreme compression fibre to centroid of tension steel, but not less than 0.8 of the overall depth, $A_{S}=$ area of shear reinforcement, $f_{Y}=y i e l d$ strength of shear reinforcement, and $s=$ spacing of shear reinforcement.

Beams

Let $v_{u}=$ shear strength from Eq. I with $v_{c}=2 \sqrt{f_{c}^{\prime}}$ psi.

Let $\mathrm{V}_{\max }=$ maximum theoretical applied shear force = beam $\mathrm{M}_{\mathrm{u}} / \mathrm{shear}$ span. The shears are tabulated below:

\begin{tabular}{ccccccccc}
\hline Unit & 1 & 2 & 3 & 4 & 5 & 6 & 7 & 8 \\
\hline $\mathrm{v}_{\mathrm{u}}$ kips & 36.6 & 57.1 & 61.6 & 56.3 & 56.7 & 67.6 & 67.5 & 59.4 \\
\hline $\mathrm{v}_{\max }$ kips & 14.2 & 16.5 & 15.9 & 15.1 & 16.5 & 16.3 & 15.2 & 14.9 \\
\hline
\end{tabular}

Hence beam shear should not be critical. Either the concrete or the stirrups could carry all the maximum possible applied shear force alone.

Columns

Let $v_{u}=$ shear strength from Eq. 1 with $v_{c}=2\left(1+0.0005 \frac{P_{u}}{A_{g}}\right) \sqrt{f_{c}^{\prime}}$ psi $=$ $3.17 \sqrt{f_{c}^{\prime}}$ psi for $P_{u}=224,0001 \mathrm{~b}$ and $A_{g}=12 \times 16 \mathrm{in}^{2}$.

Let $\mathrm{V}_{\max }=$ maximum theoretical applied shear force $=$ column $\mathrm{M}_{\mathrm{u}} / \mathrm{shear}$ span. The shears are tabulated below:

\begin{tabular}{ccccccccc}
\hline Unit & 1 & 2 & 3 & 4 & 5 & 6 & 7 & 8 \\
\hline $\mathrm{v}_{\mathrm{u}}$ kips & 53.4 & 56.6 & 56.2 & 55.0 & 58.0 & 58.4 & 58.3 & 56.8 \\
\hline $\mathrm{V}_{\max }$ kips & 35.9 & 37.4 & 37.5 & 36.4 & 37.0 & 37.2 & 37.2 & 36.2 \\
\hline
\end{tabular}

Hence column shear should not be critical.

\section{Joint Cores}

Let $v_{u}=$ shear strength from Eq. 1 with $v_{c}=3.17 \sqrt{f_{c}^{\prime}}$ psi, as for the column.

Fig. 18 shows the internal forces in the beam and the column shear acting on the joint at the theoretical ultimate moment of the beam. The beam forces are as calculated in section 9.2 and $V=M_{\mathrm{Col}} / 57^{\prime \prime}$ where $\mathrm{M}_{\mathrm{Col}}$ is the moment in the column at the face of the joint core when the beam reaches its flexural strength. Consideration of the total forces acting above or below horizontal planes across the joint (e.g. plane 1) shows that the maximum horizontal shear occurs in the middle region between the neutral axis positions of the beam sections. $\therefore$ Maximum theoretical horizontal shear force on the joint core is 


$$
\mathrm{V}_{\max }=\mathrm{T}_{4}+\mathrm{T}_{1}+\mathrm{C}_{5}+\mathrm{C}-\mathrm{T}_{3}-\mathrm{V}
$$

The shears are tabulated below:

\begin{tabular}{lccccccccc}
\hline Unit & 1 & $2^{*}$ & $3 *$ & 4 & $5 *$ & $6 *$ & 7 & $8^{*}$ \\
\hline $\begin{array}{l}\text { Shear carried by } \\
\text { concrete, kips }\end{array}$ & 35.4 & 38.6 & 38.2 & 37.0 & 37.7 & 38.1 & 38.0 & 36.3 \\
$\begin{array}{l}\text { Shear carried by } \\
\text { hoops, kips }\end{array}$ & 181.6 & 181.6 & 181.6 & 181.6 & 181.6 & 181.6 & 181.6 & 181.6 \\
\hline$v_{\mathrm{u}}$ kips & 217.0 & 220.2 & 219.8 & 218.6 & 219.3 & 219.7 & 219.6 & 217.9 \\
\hline$v_{\max }$ kips & 211.6 & 214.2 & 207.1 & 221.1 & 248.9 & 218.3 & 196.2 & 215.8 \\
\hline
\end{tabular}

* Eventually failed in joint shear in the tests after cyclic loading.

Therefore shear in the joint core should not have been critical for the units except for Unit 5 and perhaps Unit 4 (although it should be noted that the actual maximum shear forces acting at the joint core would have been greater than the tabulated $V_{\max }$ values by the increase in moments shown in Table 2). The shear reinforcement in the joint core was theoretically capable of carrying 73-93\% of the maximum theoretical shear force there.

An alternative procedure for joint core shear design would be to ignore the shear carried by the concrete and to carry the horizontal shear force entirely by the joint hoops. Inspection of the diagonal tension joint core cracks indicated that the critical failure crack appears to run from corner to corner of the joint core (see the photos of the units after testing). On this basis a possible design approach would be to ignore the shear carried by the various concrete mechanisms (aggregate interlock, etc.) and to carry all the horizontal shear by hoops crossing the critical corner to corner crack. The shear capacity of the joint core then would be $v_{u}=n A_{s} f_{y}$ where $n=$ number of hoops effectively crossing the critical crack, $A_{S}=$ area of each hoop and $f_{y}=$ yield strength of steel. Each joint core of the units contained eight hoops and if all effectively cross the critical crack the ultimate shear force on this basis is $v_{u}=8 \times 0.61 \times 43.5=212.3$ kips. This shear capacity is 85-1088 of the maximum possible shear force listed above for the units. The number of hoops effectively carrying shear across the critical crack is debatable. The hoop strain readings indicated that the hoops in the central region of the core are more effective than the hoops near the top and the bottom of the joint core. If the top and bottom hoops are disregarded, the ultimate shear force for each unit would be $v_{u}=6 \times 0.61 \times 43.5=159.2$ kips.

Tentatively, it appears that the shear carried by the concrete should be ignored. The horizontal joint shear to be allocated to the hoops should be carried by the $n$ hoops of area $A_{S}$ and yield strength $f_{y}$ which effectively cross the corner to corner crack, i.e. shear carried by hoops $=n^{\prime} f_{y}$. It is suggested that the top and bottom hoop could be disregarded and the hoops concentrated more in the central region of the core.

\subsection{Confinement Steel in Column and Joint Core}

When the column load exceeds $0.4 \mathrm{P}_{\mathrm{b}}$, where $\mathrm{P}_{\mathrm{b}}$ is the column load at balanced failure, ACI $318-71^{2}$ requires that the transverse steel in the joint region (area of rectangular hoop bar) should be at least 


$$
A_{s h}=1_{h} \rho_{s} s_{h} / 2
$$

where $\rho_{s}=0.45\left(\frac{A_{g}}{A_{c h}}-I\right) \frac{f_{c}^{\prime}}{f_{y}} \geqslant 0.12 \frac{f_{c}^{\prime}}{f_{y}}$

and $l_{h}=$ maximum unsupported length of hoop side, $s_{h}=$ spacing of hoops, $A_{G}=$ gross area of section, $A_{C h}=$ area of rectangular core to outside of hoops, $\hat{f}_{C}^{P}=$ concrete cylinder strength and $f_{y}=$ steel yield strength.

For columns of test units the applied load exceeded $0.4 \mathrm{P}_{\mathrm{b}}$ and was in the order of $0.6 \mathrm{P}_{\mathrm{b}}$. The required spacing of No.5 hoops in the columns and joint cores of the units according to Eq. 3 varied between 1.70 and $2.02 \mathrm{in}$. The hoops present in the joint cores were at $2 \mathrm{in}$. centres and hence the ACI requirement was almost met there. Elsewhere in the columns no attempt was made to meet this requirement because plastic hinges were not expected in the columns.

\subsection{Bond Forces in Joint Cores}

Reference to Fig. 18 shows that substantial bond forces need to be transferred to the concrete of the joint core by bond if the beam forces are to develop as calculated. The bond forces when the flexural strength is developed are

$$
\begin{aligned}
& B_{1}=T_{4}+C_{5} \\
& B_{2}=T_{1}-T_{3}
\end{aligned}
$$

It is to be noted that the bond force from the central tendon is zero. The bond forces $B_{1}$ and $B_{2}$ can be divided among the bars contributing according to the number of bars and their relative areas. The maximum bond force per bar in each unit so found, calculated using the beam forces of section 9.2, are tabulated below:

\begin{tabular}{ccccccccc}
\hline Unit & 1 & 2 & 3 & 4 & 5 & 6 & 7 & 8 \\
\hline $\begin{array}{l}\text { Max. bond force per } \\
\text { bar from B , kips }\end{array}$ & 9.0 & 69.9 & 52.8 & 10.4 & 10.4 & 29.1 & 36.4 & 10.7 \\
\hline $\begin{array}{l}\text { Max. bond force per } \\
\text { tendon from B , kips }\end{array}$ & 33.4 & - & - & 32.4 & 54.2 & - & 23.9 & 23.7 \\
\hline
\end{tabular}

Some comparison of the level of these bond forces with the level normally allowed for anchorage is of interest. According to ACI 318-71 the basic development length for deformed bars, No. 11 or smaller, in tension is $l_{\mathrm{d}}=0.04 \mathrm{~A}_{\mathrm{b}} \mathrm{f}_{\mathrm{y}} / \sqrt{\mathrm{f}} \mathrm{c}_{\mathrm{c}}$ but not less than $0.0004 \mathrm{~d}_{\mathrm{b}} \mathrm{f}_{\mathrm{y}}$; where $\mathrm{A}_{\mathrm{b}}=$ bar area, $d_{b}=$ bar diameter, $f_{y}=$ bar yield strength, $f_{c}^{\prime}=$ concrete cylinder strength and all units are $1 \mathrm{~b}$ and in. This means an average ultimate bond force $A_{b} f_{y} / l_{d}=\sqrt{f_{c}^{\prime}} / 0.04 \mathrm{lb}$ per in, but not greater than $1960 d_{b} 1 b$ per in. The concrete strength of the test units was in the range 4630-5510 psi. If a mean value of $f_{C}^{\prime}=5000 \mathrm{psi}$ is assumed the ultimate bond force which can be developed over the 16 in depth of column by a bar in tension is approximately

$$
\begin{aligned}
\mathrm{B}_{\mathrm{u}} & =16 \sqrt{5000} / 0.04 \mathrm{lb} \text {, but not greater than } 16 \times 1960 \mathrm{~d}_{\mathrm{b}} 1 \mathrm{~b} \\
& =28.3 \mathrm{kips} / \mathrm{bar} \text {, but not greater than } 31.4 \mathrm{~d} \mathrm{~b} \text { kips/bar. }
\end{aligned}
$$


The bond strength in tension has been used because although part of the bar is in compression there is no end bearing of the bar and hence the code development length expression for a bar in compression does not apply. Taking the above value for $B_{u}$ as a guide, the ultimate bond forces for the reinforcing bars making up the $B_{1}$ forces are 11.8 kips for the No. 3 bars (Units 1, 4, 5 and 8). 23.6 kips for the No. 6 bars (Units 6 and 7) and 28.3 kips for the No.9 bars (Units 2 and 3 ). On this basis, referring to the previously tabulated maximum bond forces per bar, it is apparent that the reinforcing bars of Units 2,3 and 7 had a particularly severe bond condition. This was reflected in the tests by slip of the bars of Units 2 and 3 . Note also that the tendons of Unit 5 apparently had a severe bond condition. However the above value of $B_{u}$ is based on bond failure by concrete splitting (i.e. $B_{u}$ is a function of $\left.\sqrt{ } f_{C}\right)^{\prime}$; for bars or tendons embedded deep in a section, for example passing through the central region of a column, the above value of $B_{u}$ is conservative.

It should be noted that high bond forces will contribute to joint core failure because of the necessity to transfer this force across the joint by diagonal tension forces. A more favourable situation for the joint core is when the compressive forces from the members are mainly due to concrete compression. Concrete compression forces can be transferred across the joint core by a concrete compressive strut. A comparison of the actions on the joint due to steel forces and concrete forces is illustrated in Fig. 19. It is evident that for favourable joint core behaviour the steel bond forces must not be excessive. Note that a prestressing tendon at mid depth does not apply bond forces and hence is favourably situated from the point of view of joint core behaviour. Also, unbonded prestressed tendons are particularly favourable because no bond forces are involved regardless of where they are placed and all the shear in the joint core can be carried from corner to corner by a concrete compressive strut.

\section{Summary}

The report describes test results obtained from eight full-scale concrete beam-column frame assemblies subjected to static cyclic loading simulating the effect of earthquake loading. The frame members contained a range of proportions of prestressing steel and ordinary reinforcing steel. Information concerning inelastic deformation capacity and degree of damage was obtained.

The behaviour of the frames emphasized the need for transverse steel in the plastic hinge zones and in the joint cores to ensure ductile behaviour and to avoid diagonal tension failure. The procedure of ACI 318-71 for joint core shear design did not prevent failure of some joint cores when large inelastic displacements simulating intense seismic loading were imposed. 


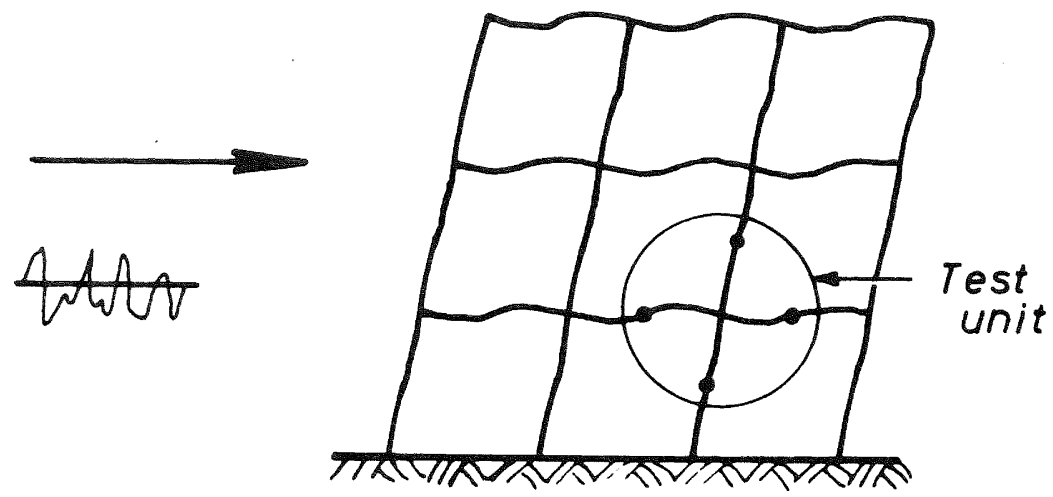

Fig. I Building Frame Subjected to Earthquake Motions.

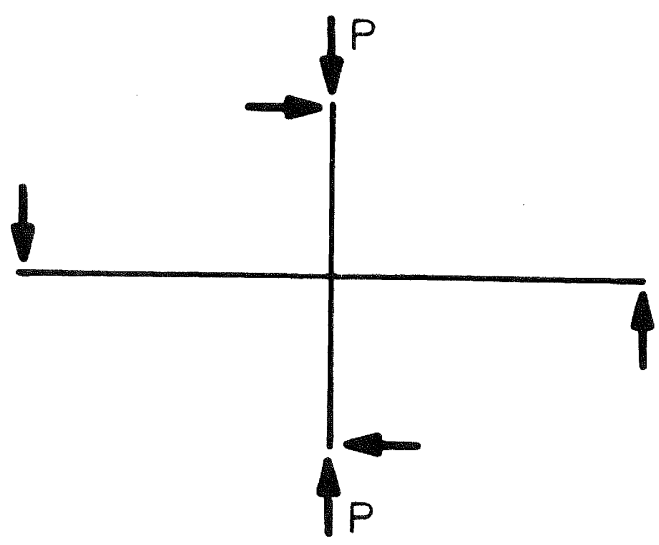

Fig. 2 Loading Simulating the Action of an Earthquake on the Beam-Column Test Unit.
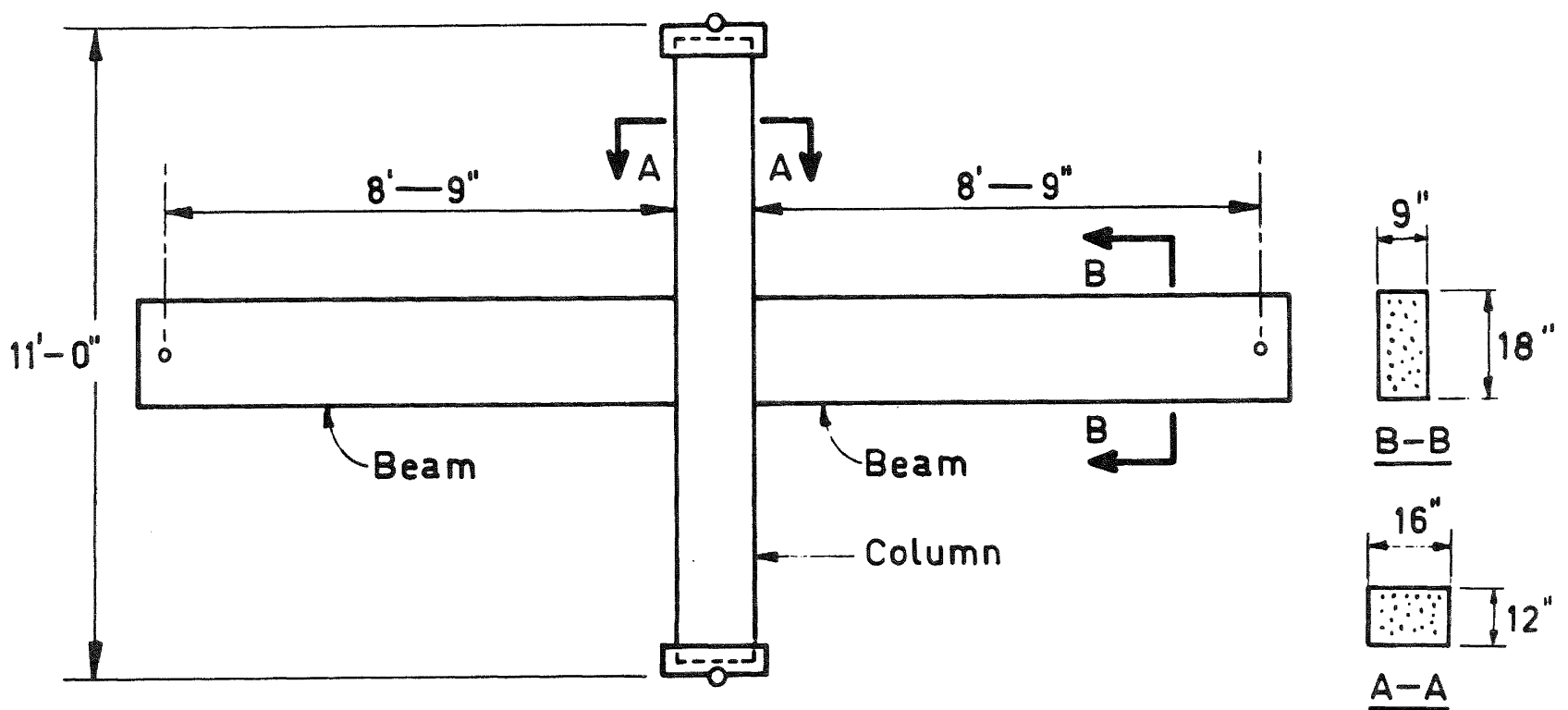

Fig. 3 Dimensions of Beam-Column Units. 


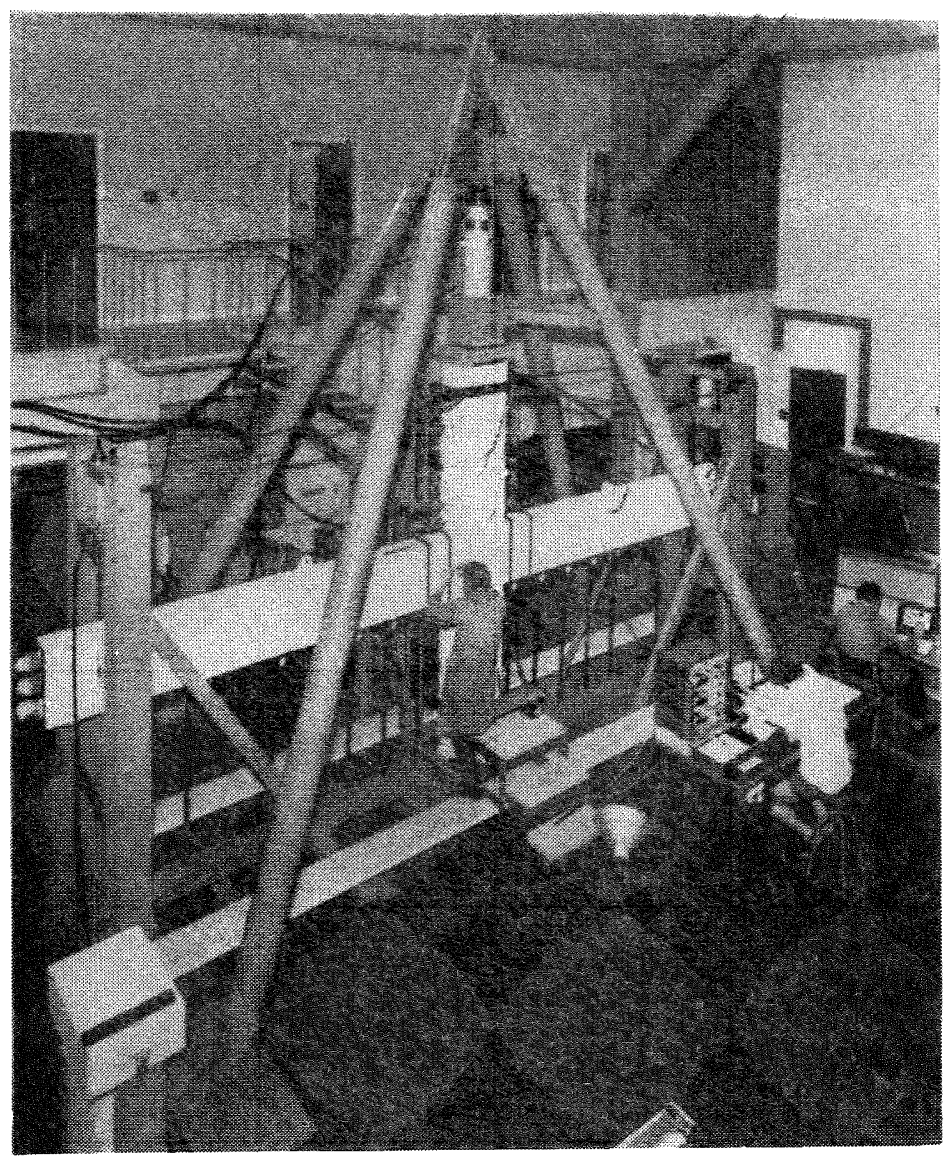

Fig. 4 Unit in Test Frame During Testing.

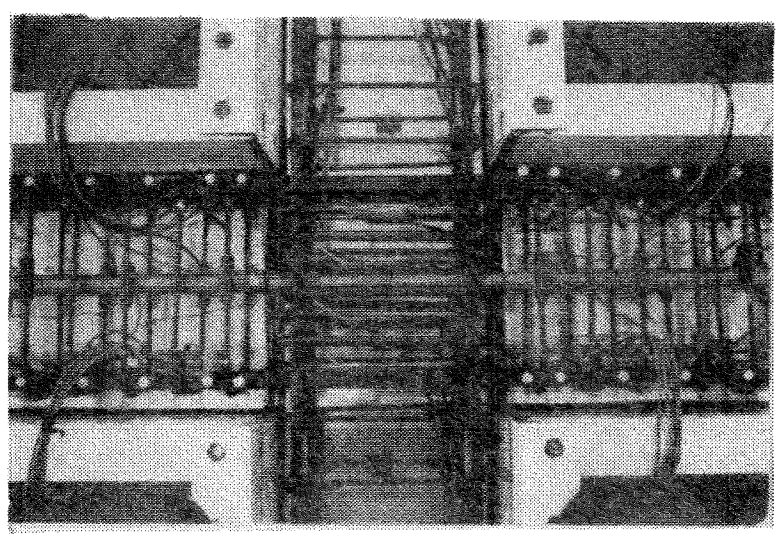

Fig. 5 Unit 2 Steel

Before Placing Concrete.

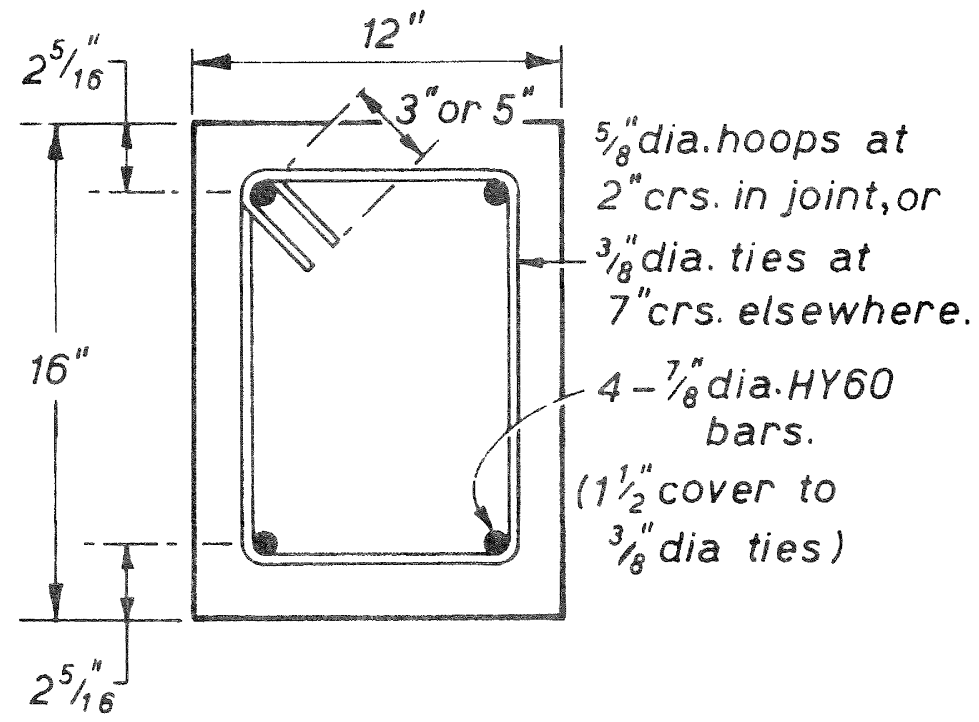

Fig. 6 Column for All Units. 


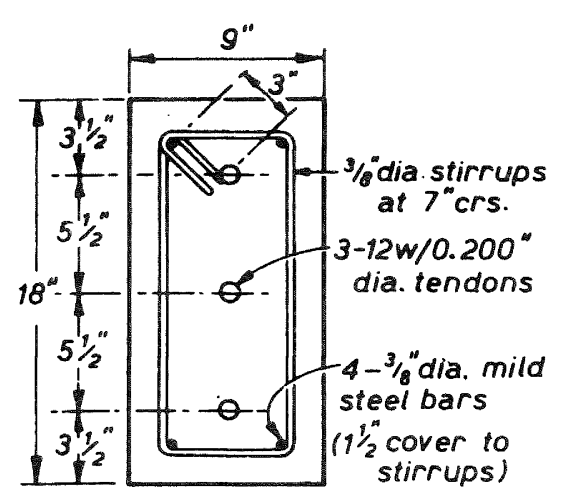

Unit 1

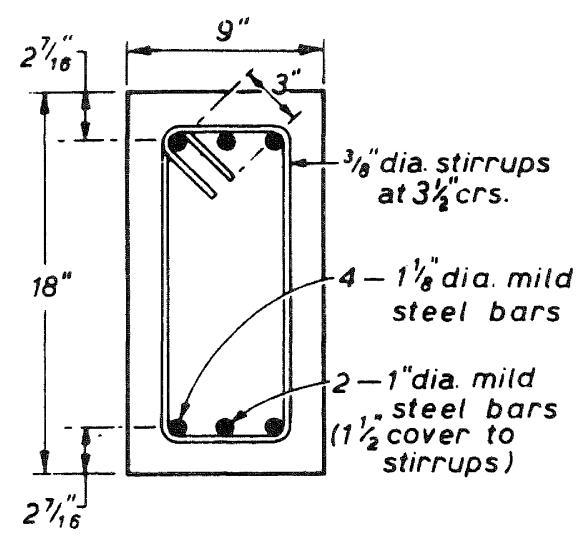

Unit 3

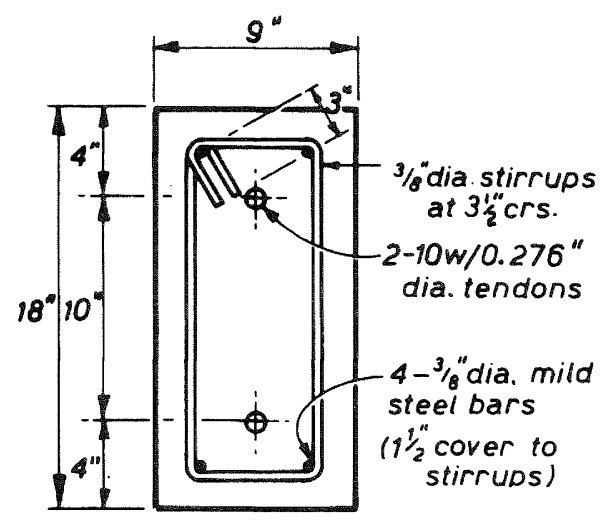

Unit 5

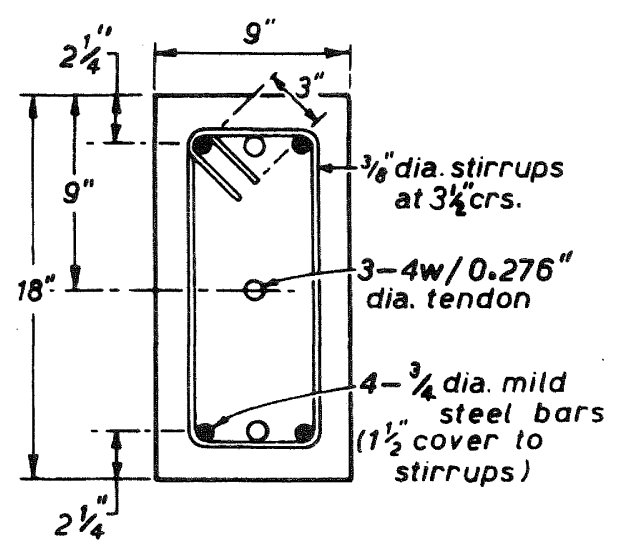

Unit 7

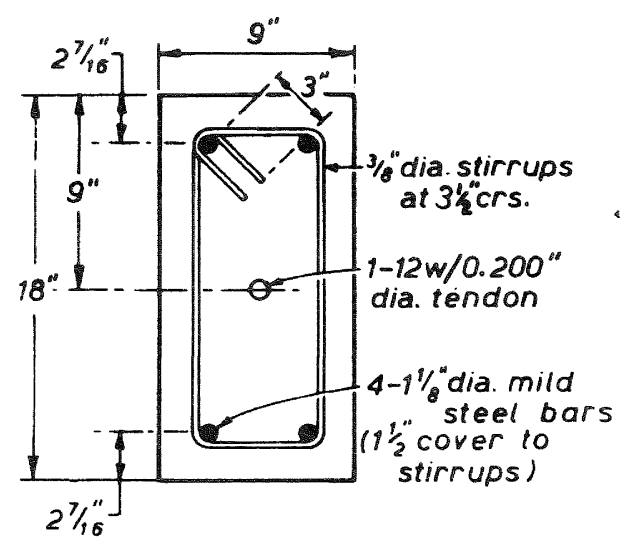

Unit 2

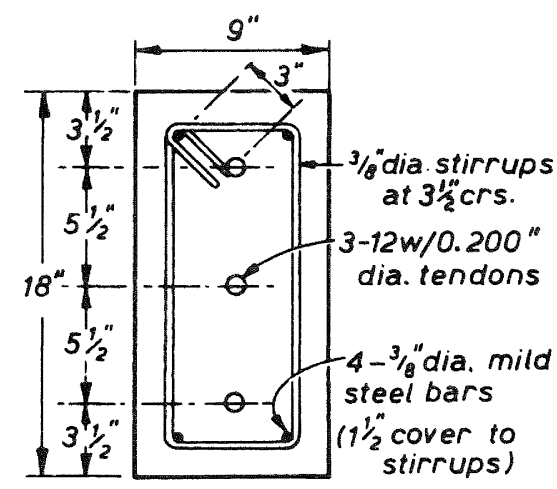

Unit 4

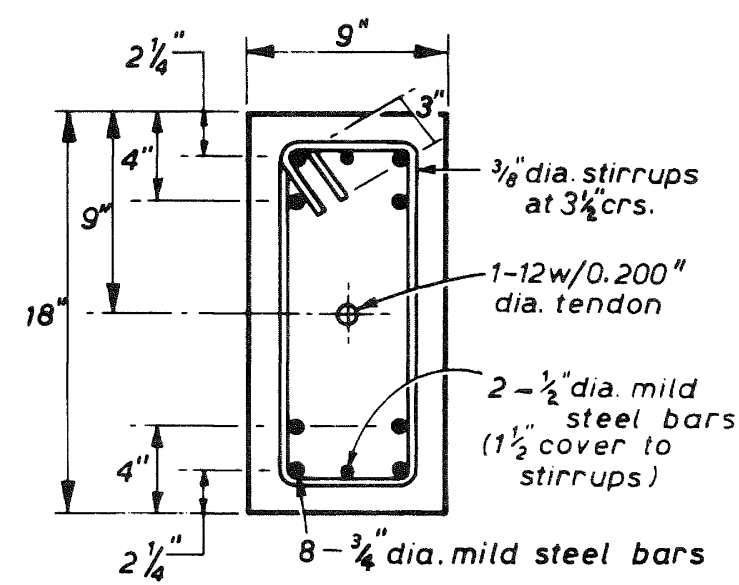

Unit 6

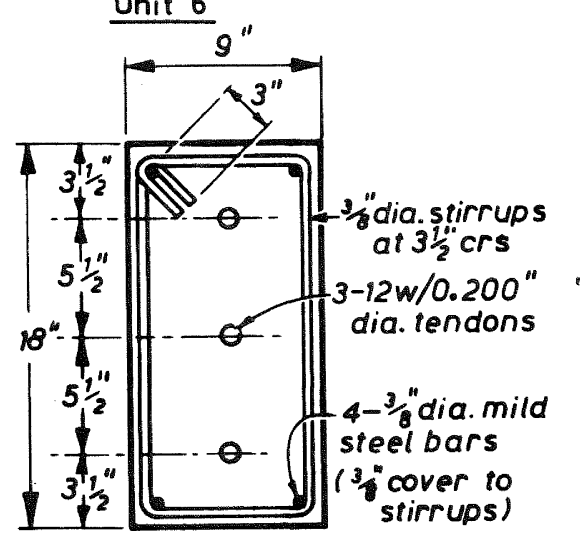

Unit 8

Fig. 7 Beam Sections of Units. 


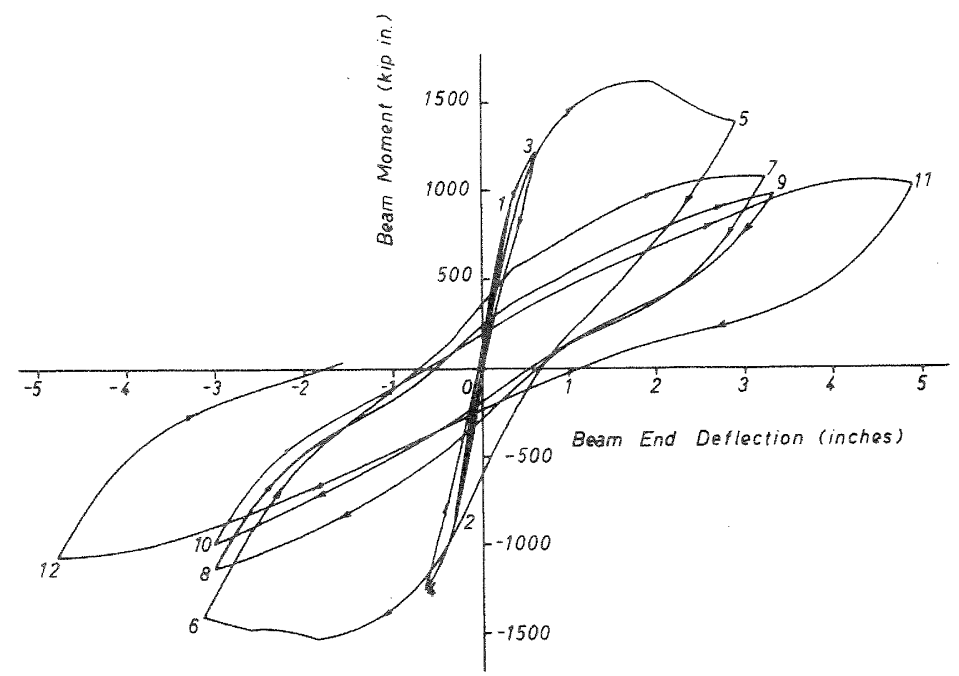

Fig. 8a Unit I Beam Moment at Column Face Versus Left Beam End Deflection.

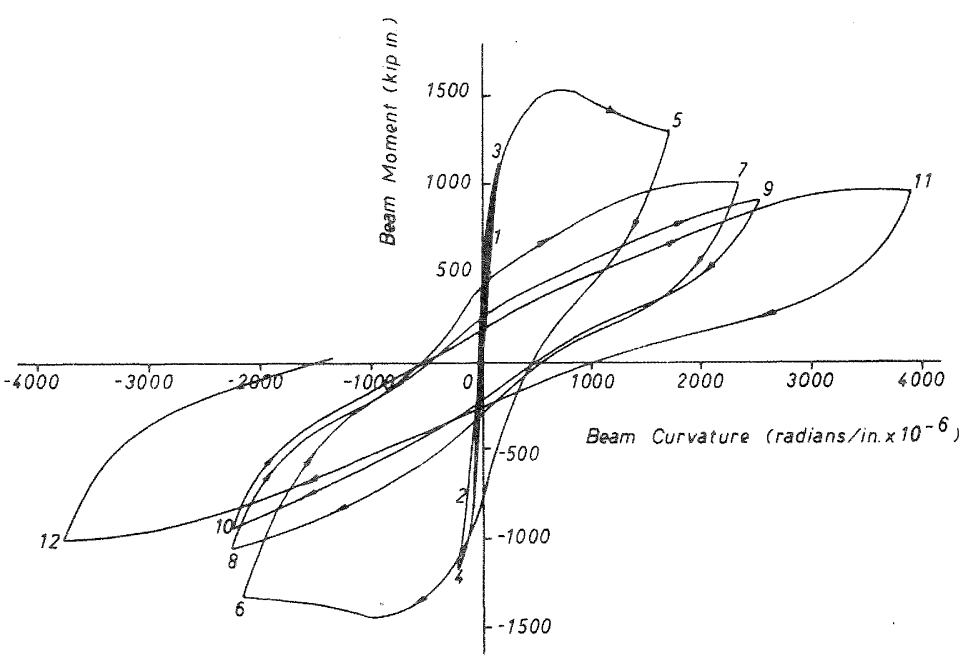

Fig. 8b Unit I Beam Moment at 6 in from Column Face Versus Average Curvature in Left Beam Over 12 in Gauge Length Adjacent to Column Face.

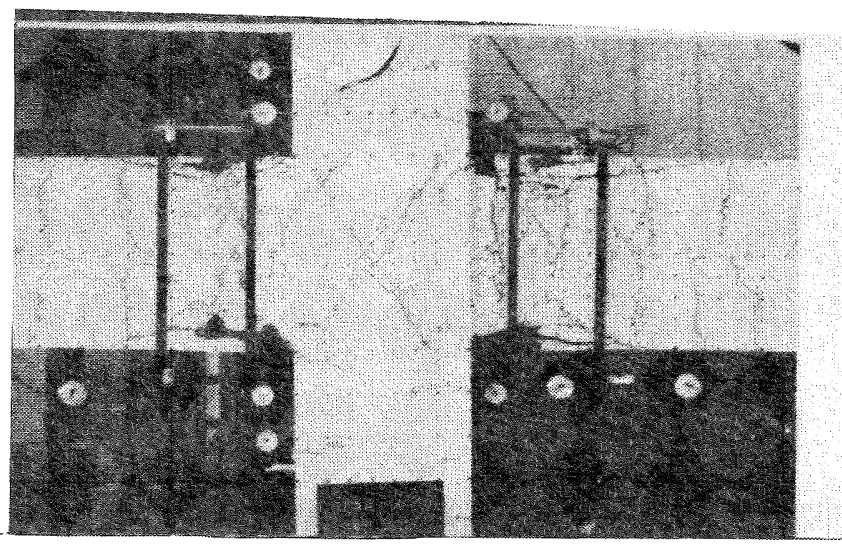

Fig. $8 \mathrm{C}$ Unit 1

At Maximum Moment (End of Loading Run 6)

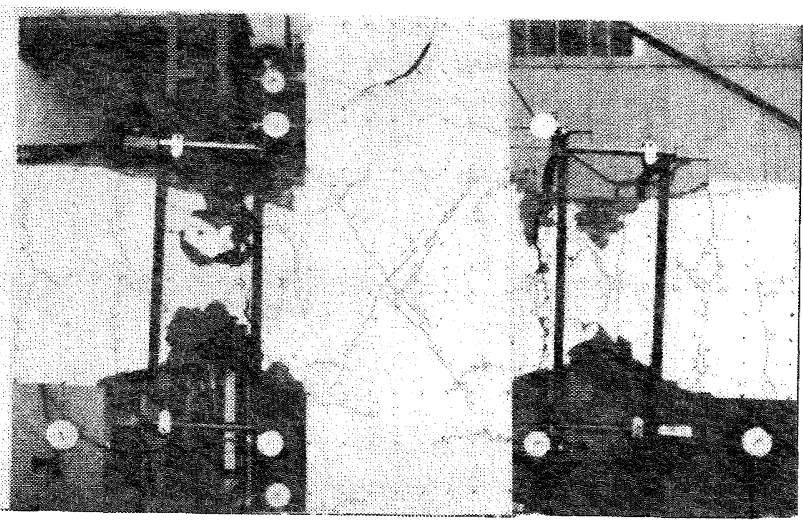

Fig. 8d Unit 1

At Maximum Deflection (End of Loading Run 12) 


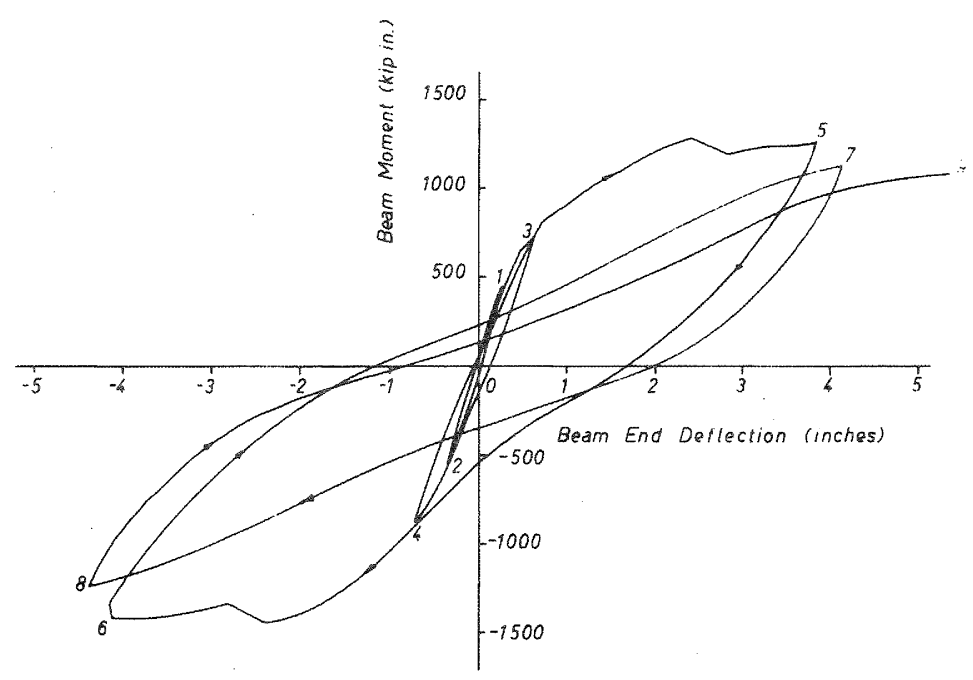

Fig. 9a Repaired Unit I Beam Moment at Column Face Versus Left Beam End Deflection.

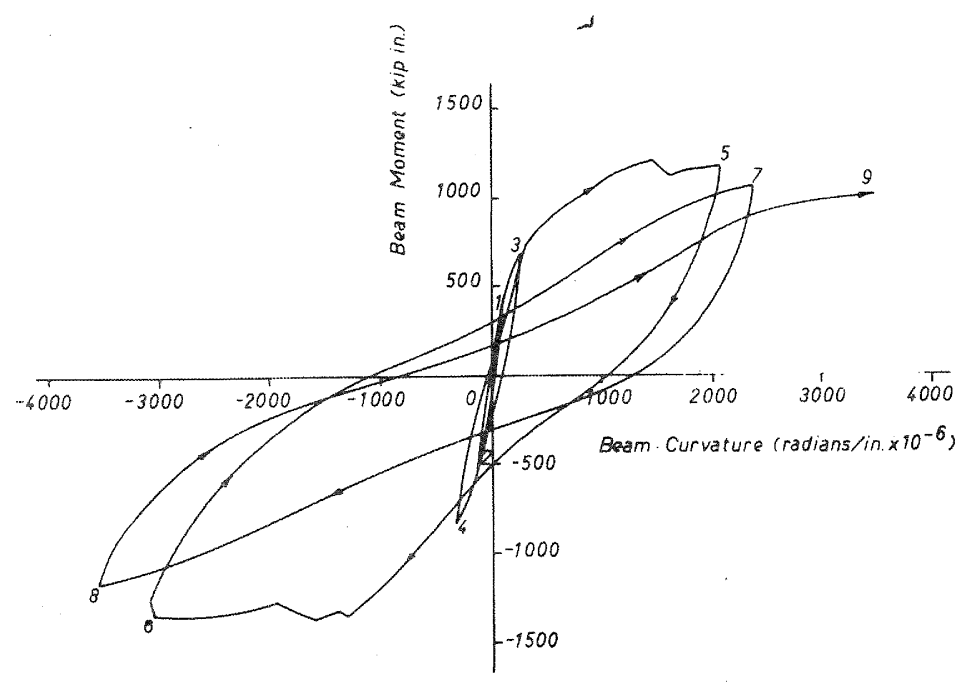

Fig. 9b Repaired unit 1 Beam Moment at 6 in from Column Face Versus Average Curvature in Left Beam Over 12 in Gauge Length Adjacent to Column Face.

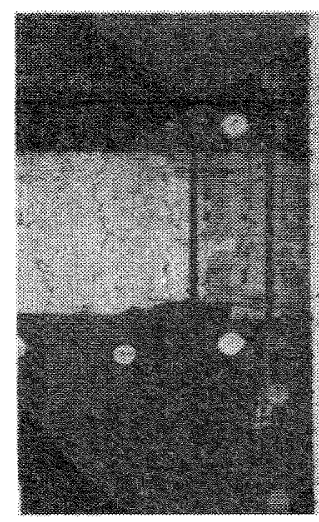

Fig. 9c Repaired Unit 1 At Maximum Moment

(End of Loading Run 6).

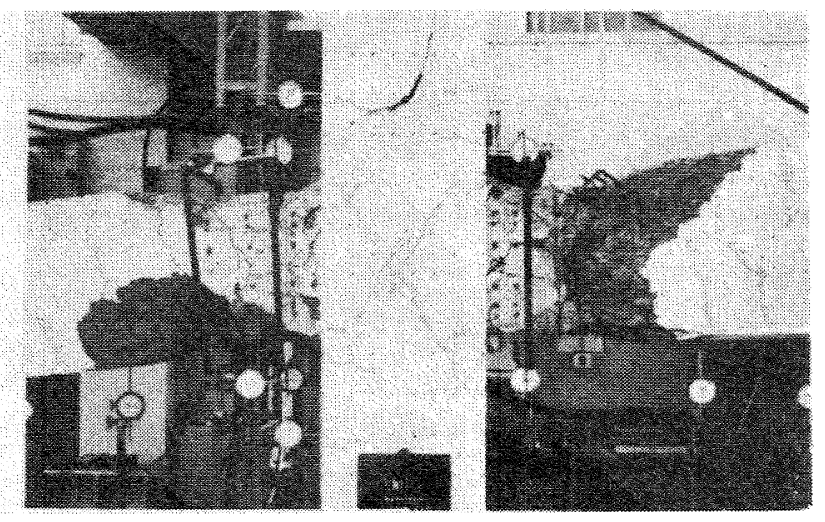

Fig. 9d Repaired Unit 1 At Maximum Deflection

(End of Loading Run 9). 


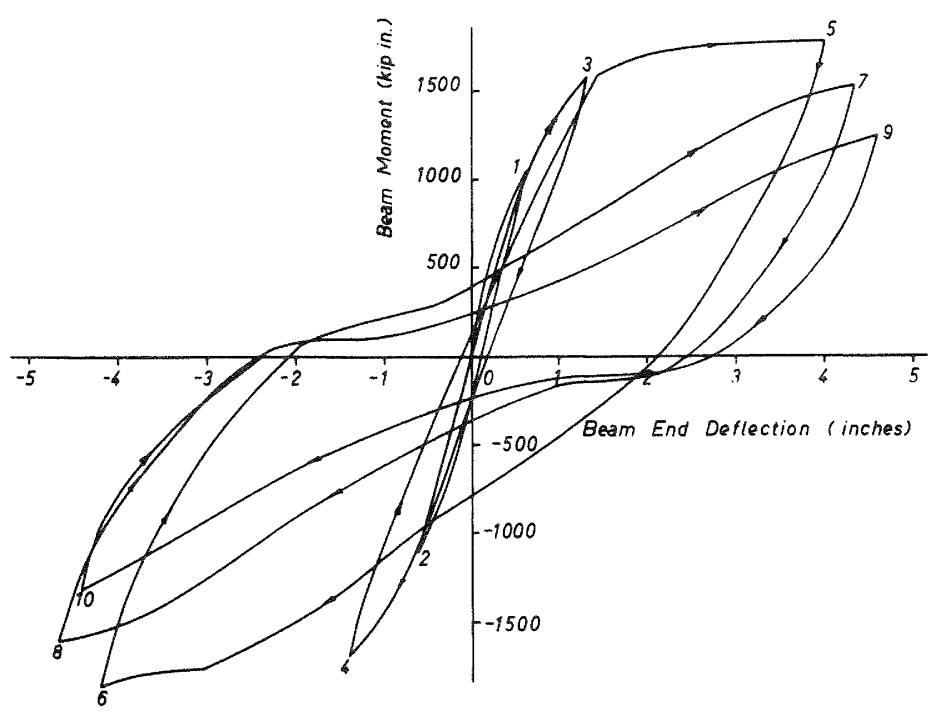

Fig. loa Unit 2 Beam Moment at Column Face Versus Left Beam End Deflection.

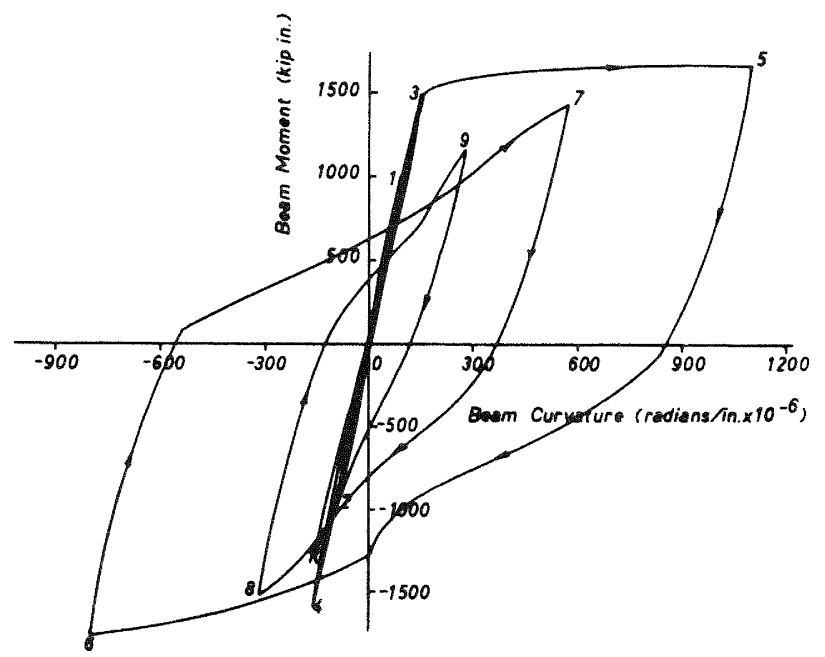

Fig. lob Unit 2 Beam Moment at 6 in From Column Face Versus Average Curvature in Left Beam Over 10 in Gauge Length 1 in From Column Face.

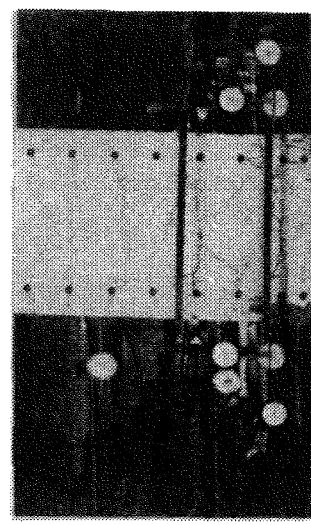

Fig. 10c Maximum Moment (End of Loading Run 6).

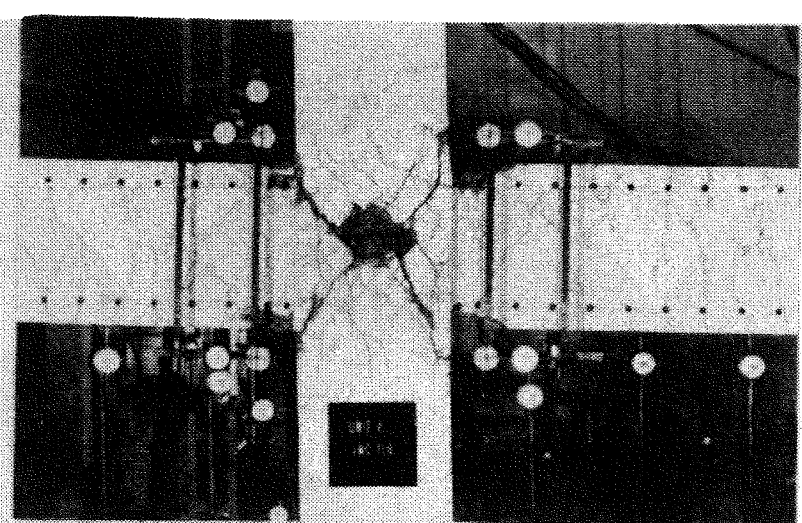

Fig. 10d Unit 2 At Maximum Deflection (End of Loading Run 10). 


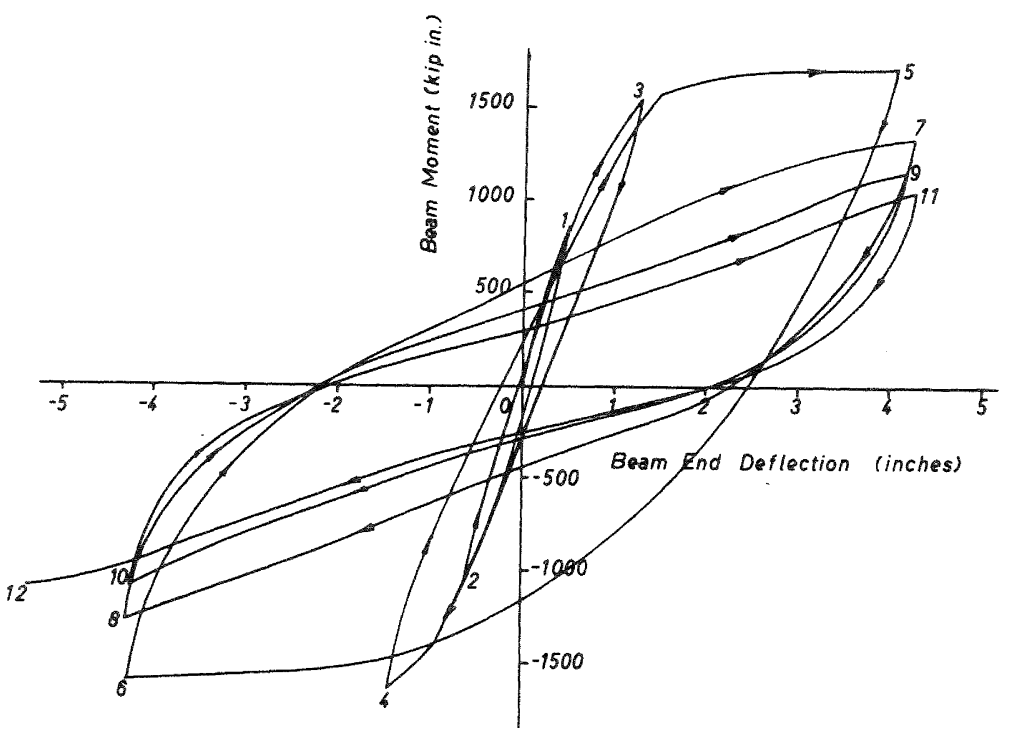

Fig. Ila Unit 3 Beam Moment at Column Face Versus Left Beam End Deflection.

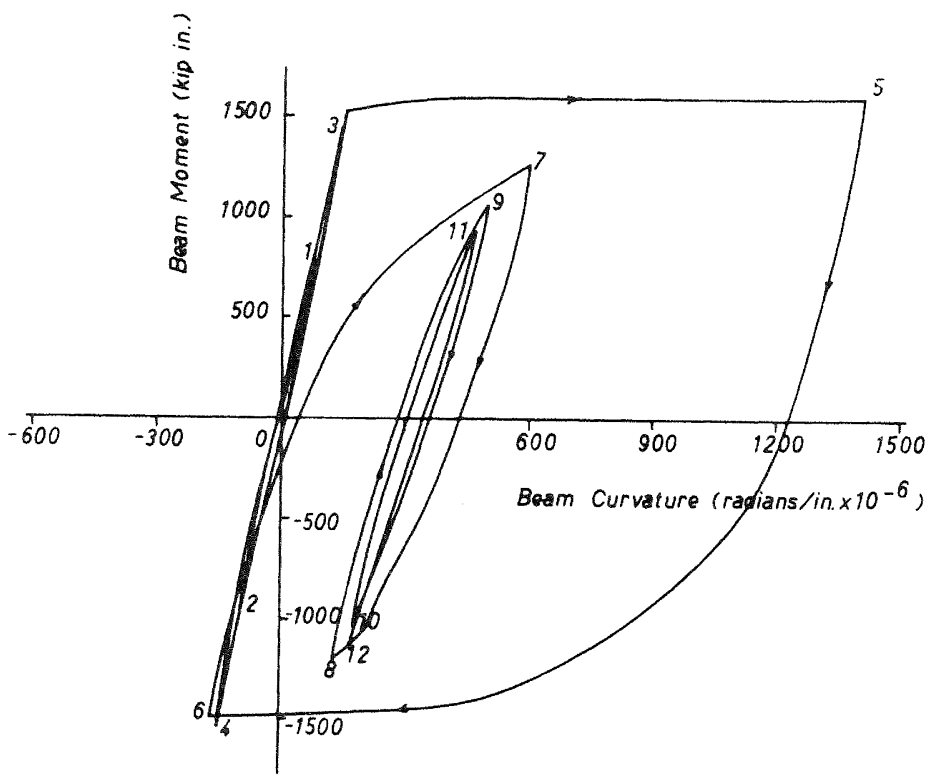

Fig. Ilb Unit 3 Beam Moment at 6 in from Column

Face Versus Average Curvature in Left Beam

Over 10 in Gauge Length 1 in from Column Face.

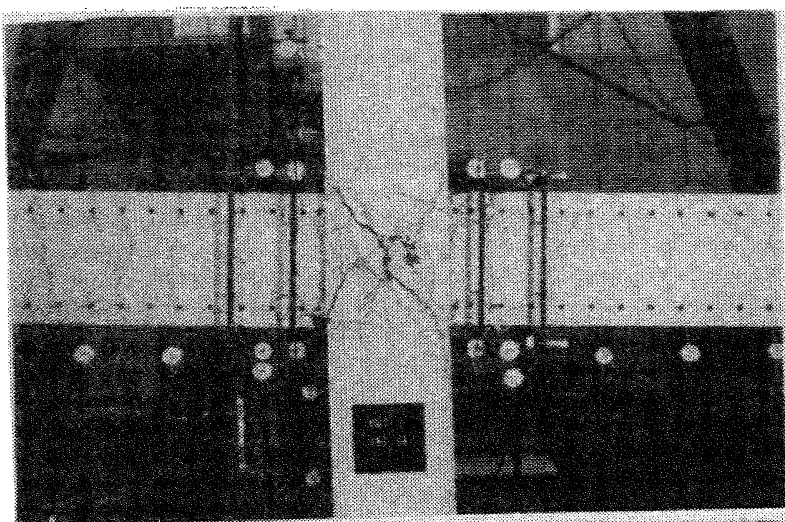

Fig. 1lc Unit 3 at Maximum Moment (End of Loading Run 6).

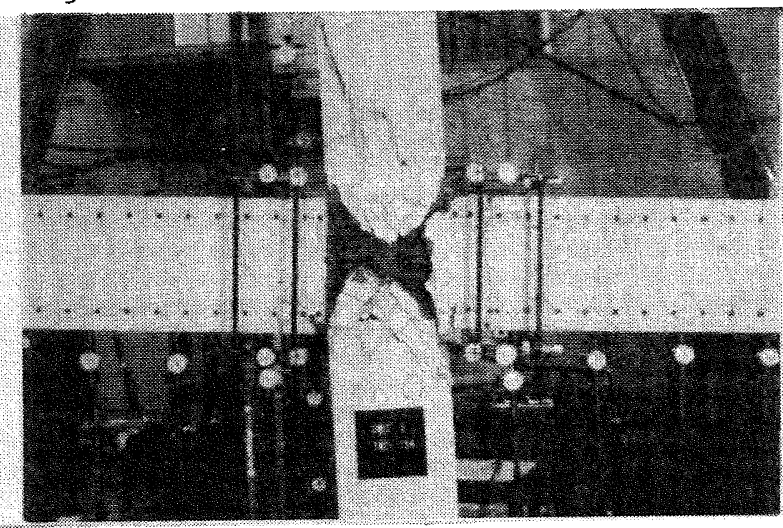

Fig. Ild Unit 3 at Maximum Deflection (End of Loading Run 12). 


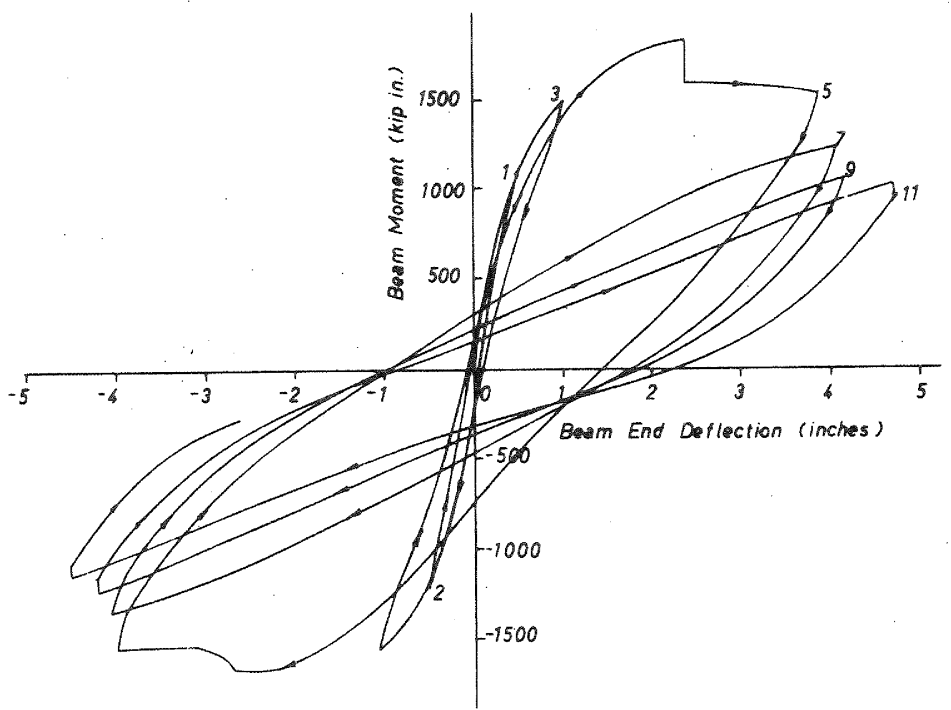

Fig. 12a Unit 4 Beam Moment at Column Face Versus Left Beam End Deflection.

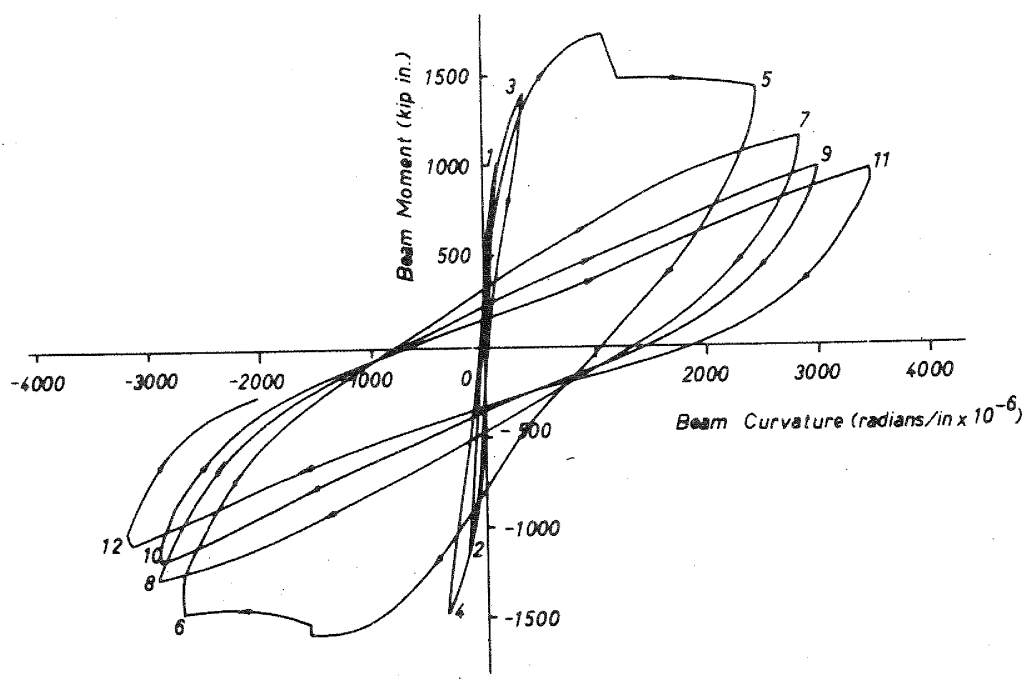

Fig. 12b Unit 4 Beam Moment at 6 in From Column Face Versus Average Curvature in Left Beam Over 12 in Gauge Length Adjacent to Column Face.

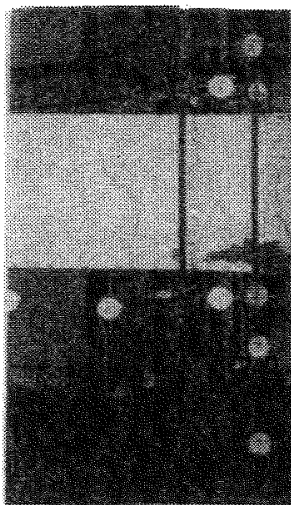

Fig. $12 \mathrm{C}$
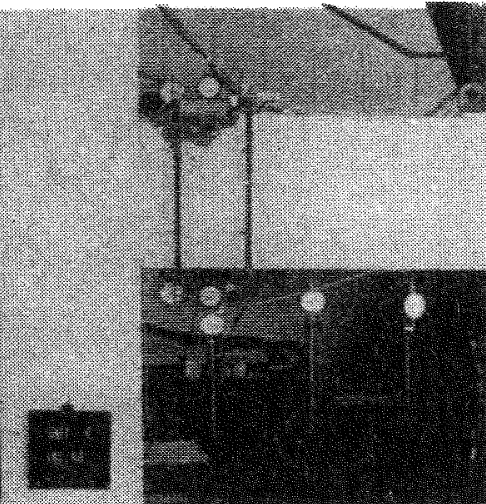

Unit 4 at

Maximum Moment

(End of Loading Run 6).

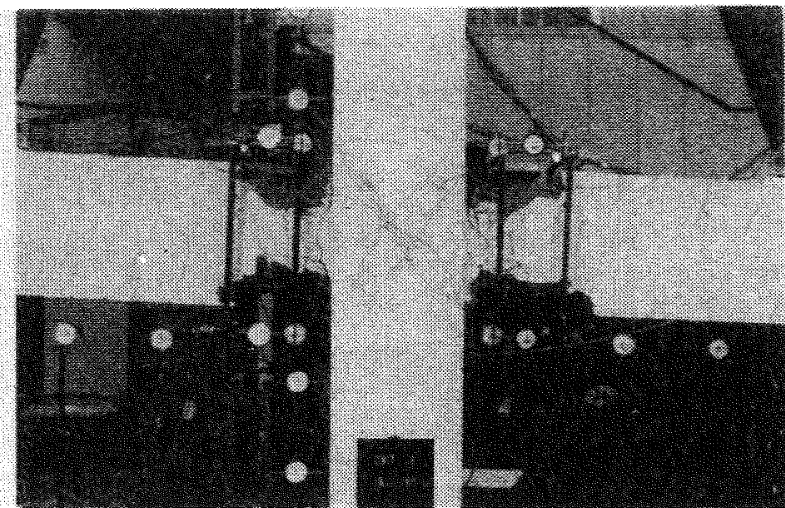

Fig. 12d Unit 4 At

Maximum Deflection

(End of Loading Run 12). 


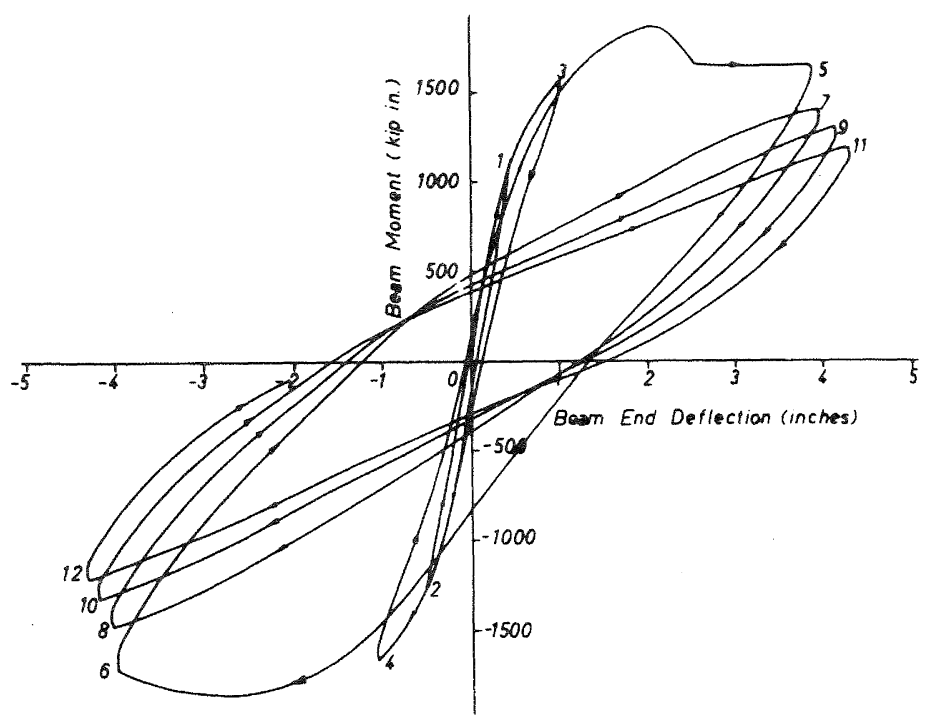

Fig. 13a Unit 5 Beam Moment at Column Face Versus Left Beam End Deflection

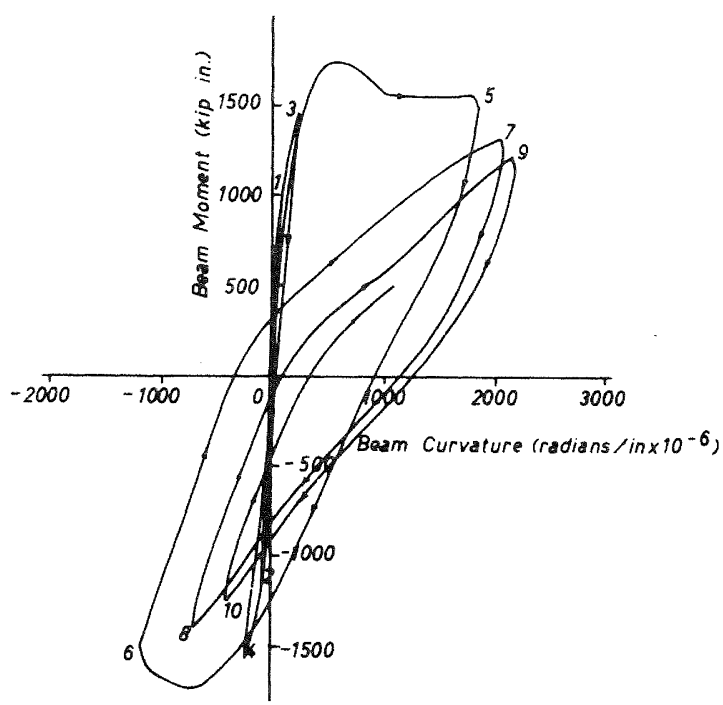

Fig. 13b Unit 5 Beam Moment at 6 in From Column Face Versus Average Curvature in Left Beam Over 12 in Gauge Length Adjacent to Column Face.

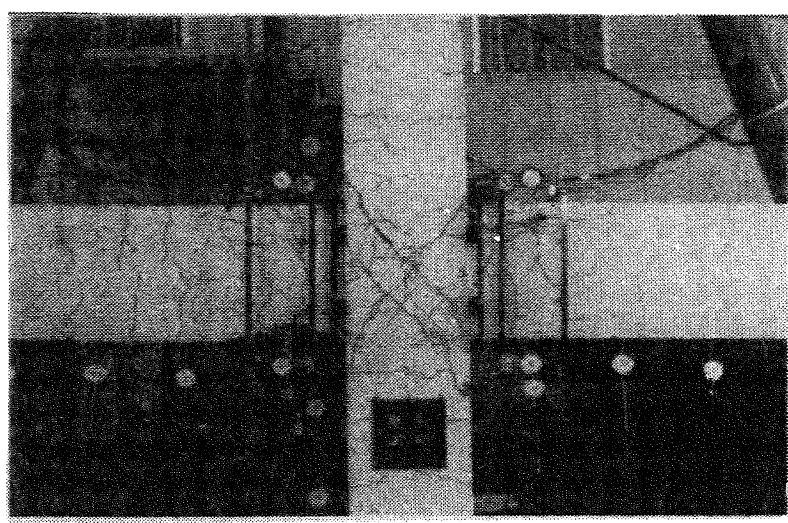

Fig. 13c Unit 5 At

Maximum Moment

(End of Loading Run 6).

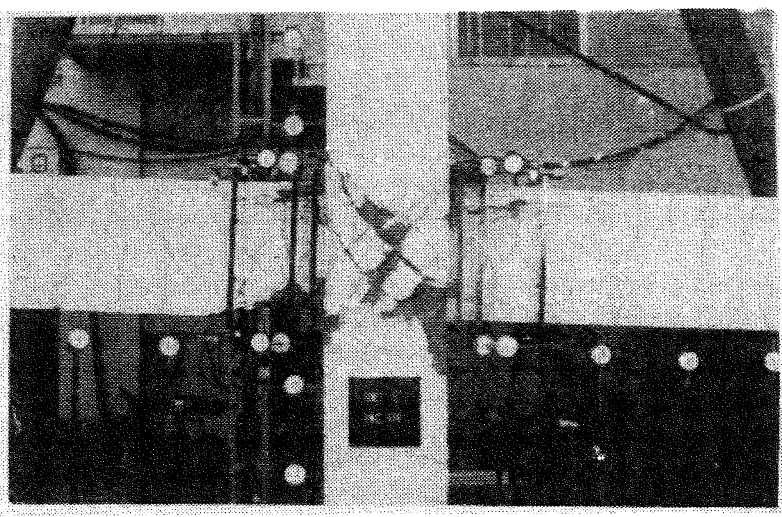

Fig. 13d Unit 5 At Maximum Deflection (End of Loading Run 12). 


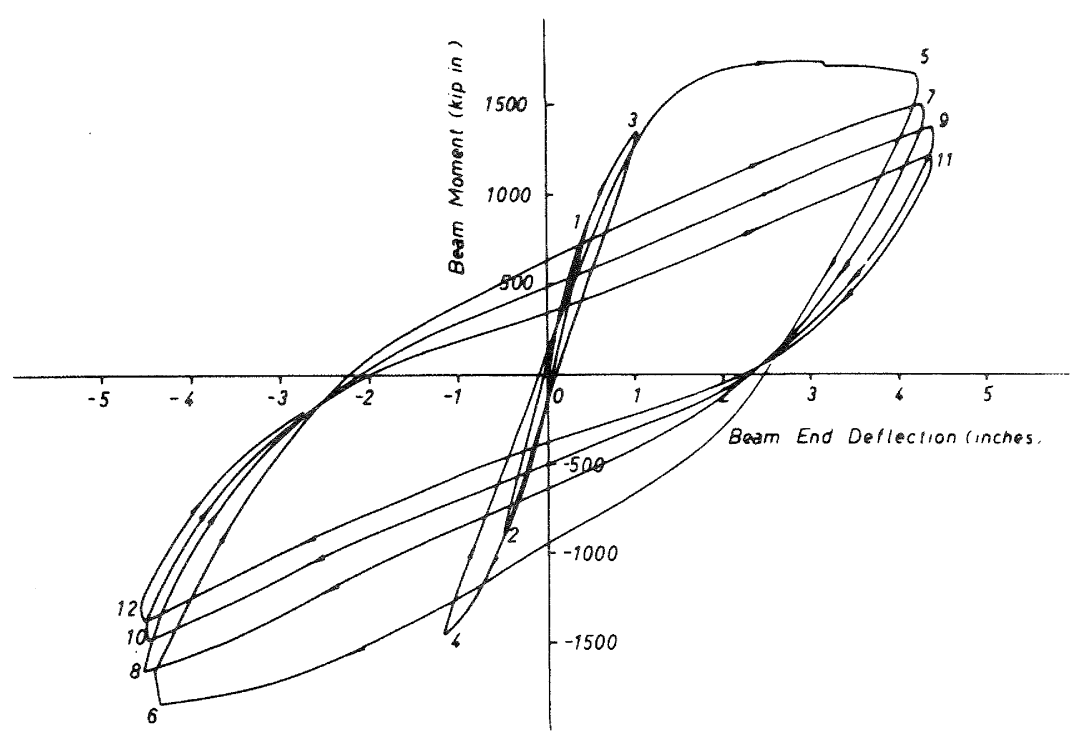

Fig. I4a Unit 6 Beam Moment at Column Face Versus Left Beam End Deflection.

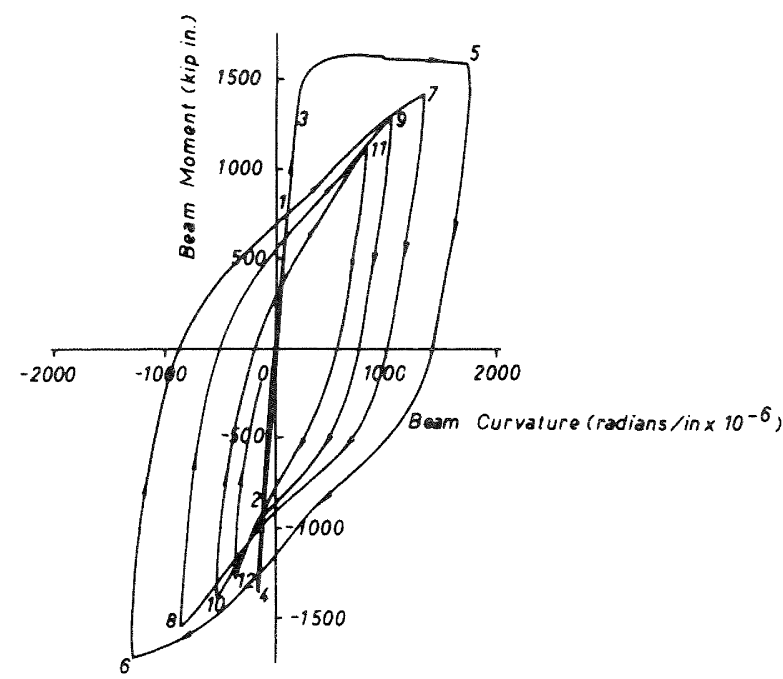

Fig. 14b Unit 6 Beam Moment at 6 in From Column Face Versus Average Curvature in Left Beam Over 12 in Gauge Length Adjacent to Column Face.

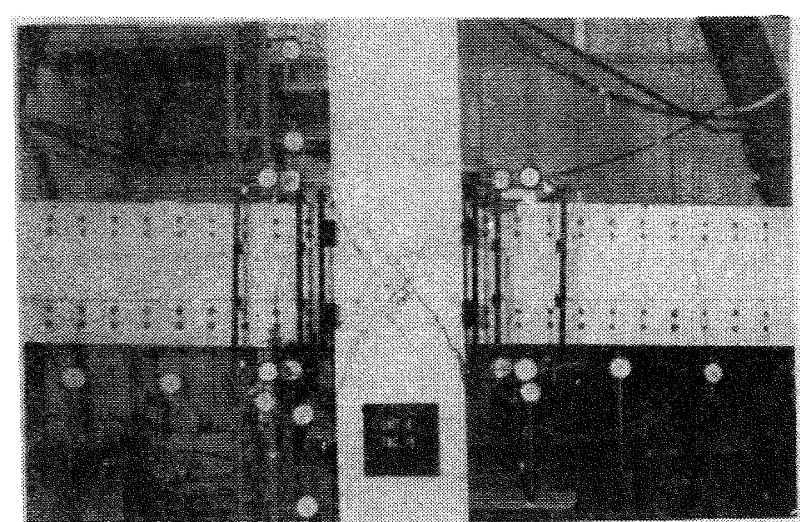

Fig. 14c Unit 6 At Maximum Moment

(End of Loading Run 6).

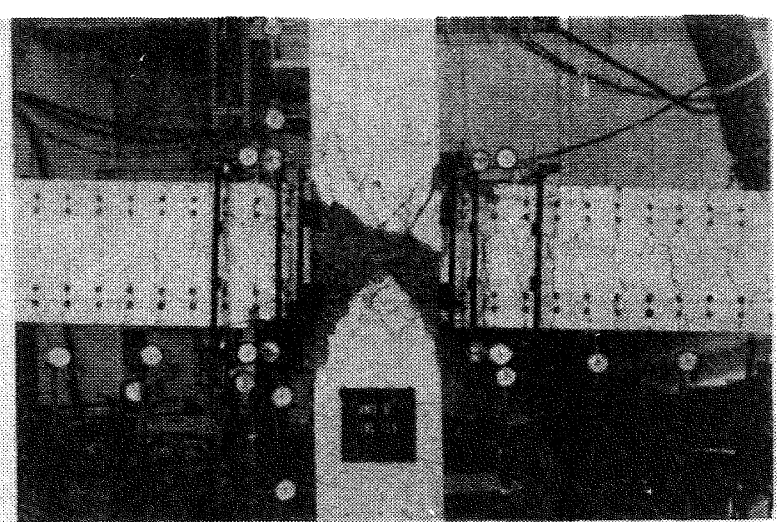

Fig. 14d Unit 6 At Maximum Deflection

(End of Loading Run 12). 


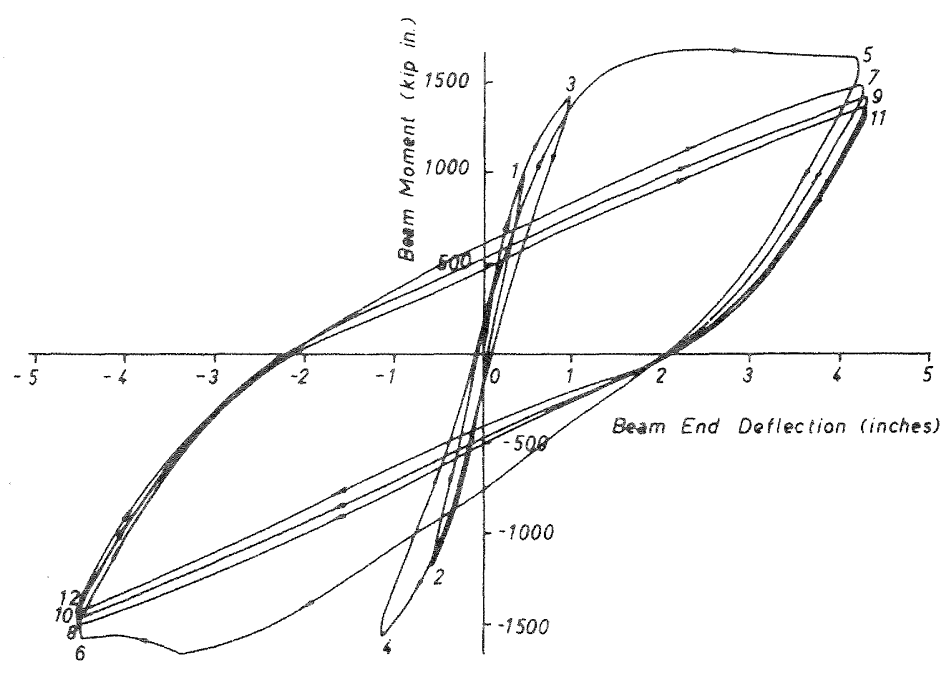

Fig. $15 a$ Unit 7 Beam Moment at Column Face Versus Left Beam End Deflection.

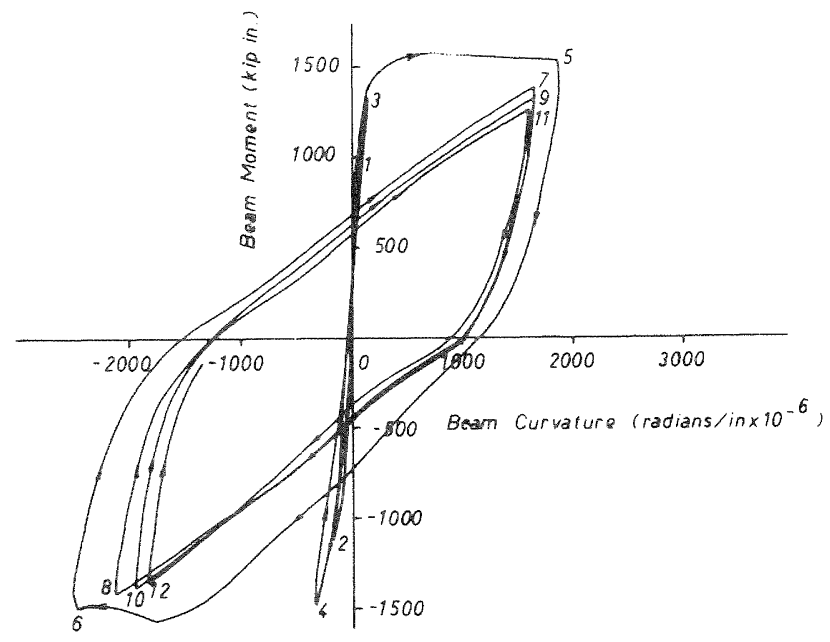

Fig. 15b Unit 7 Beam Moment at 6 in From column Face Versus Average Curvature in Left Beam Over 12 in Gauge Length Adjacent to column Face.

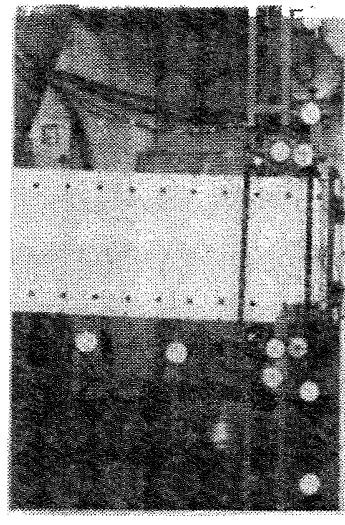

Eig. $15 \mathrm{C}$ Unit 7 At Maximum Moment

(End of Loading Run 6).

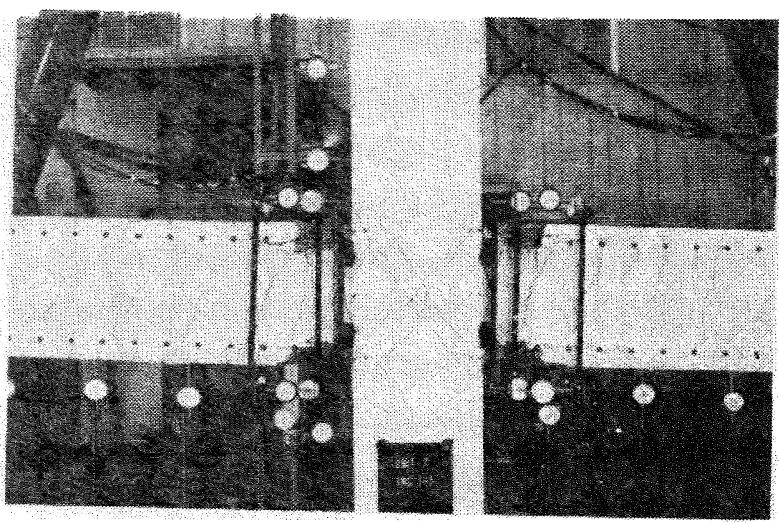

Fig. 15d Unit 7 At Maximum Deflection

(End of Loading Run 12). 


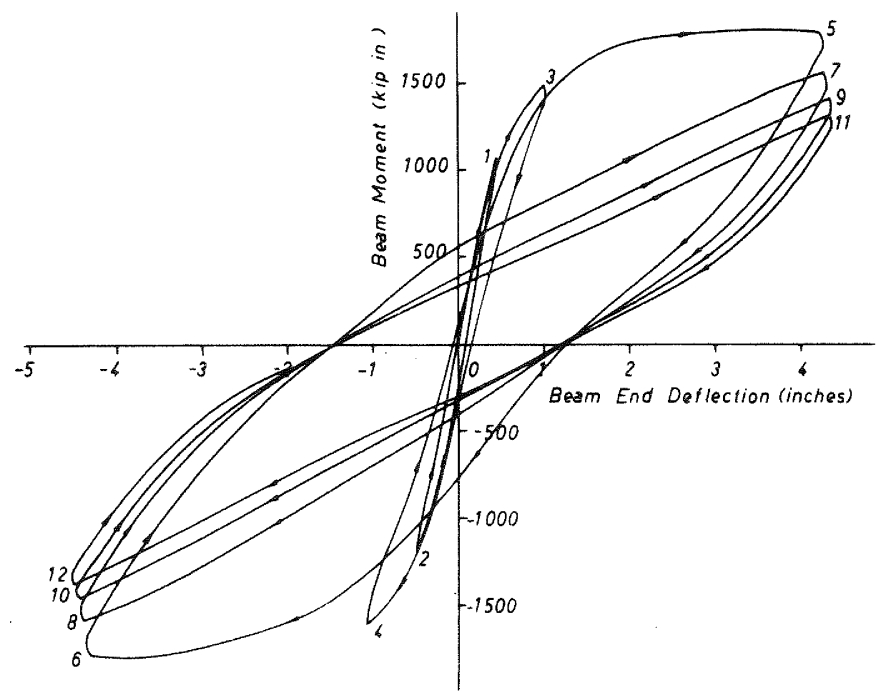

Fig. 16a Unit 8 Beam Moment at Column Face Versus Left Beam End Deflection.

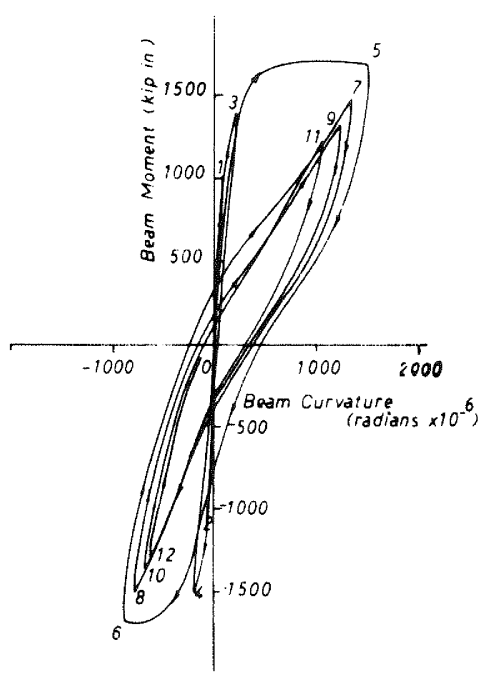

Fig. 16b Unit 8 Beam Moment at 6 in From Column Face Versus Average Curvature in Left Beam Over 12 in Gauge Length Adjacent to Column Face.

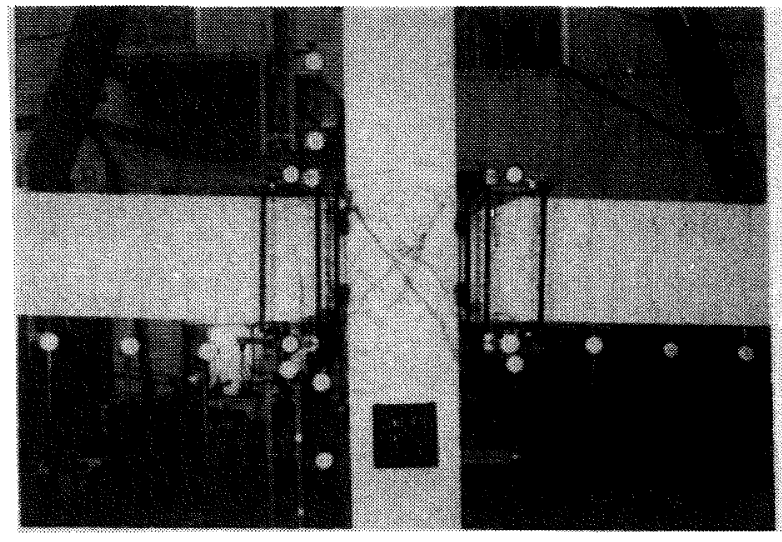

Fig. 16C Unit 8 At Maximum Moment (End of Loading Run 6).

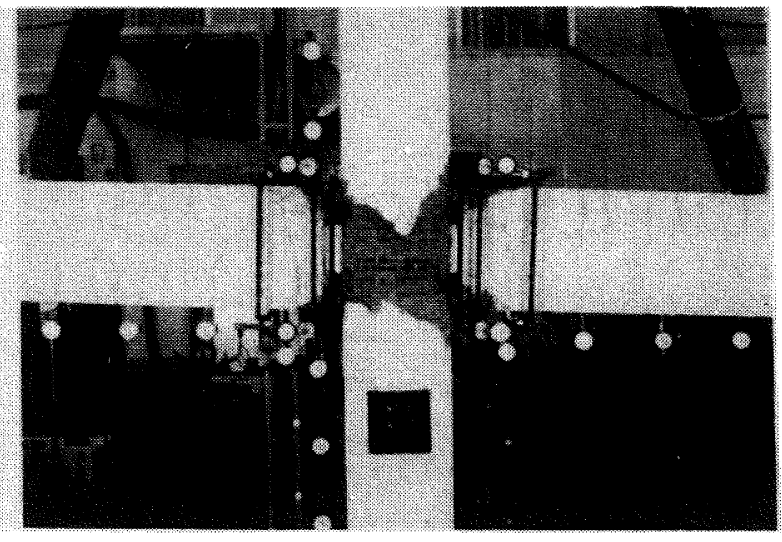

Fig. 16d Unit 8 At Maximum Deflection (End of Loading Run 12). 


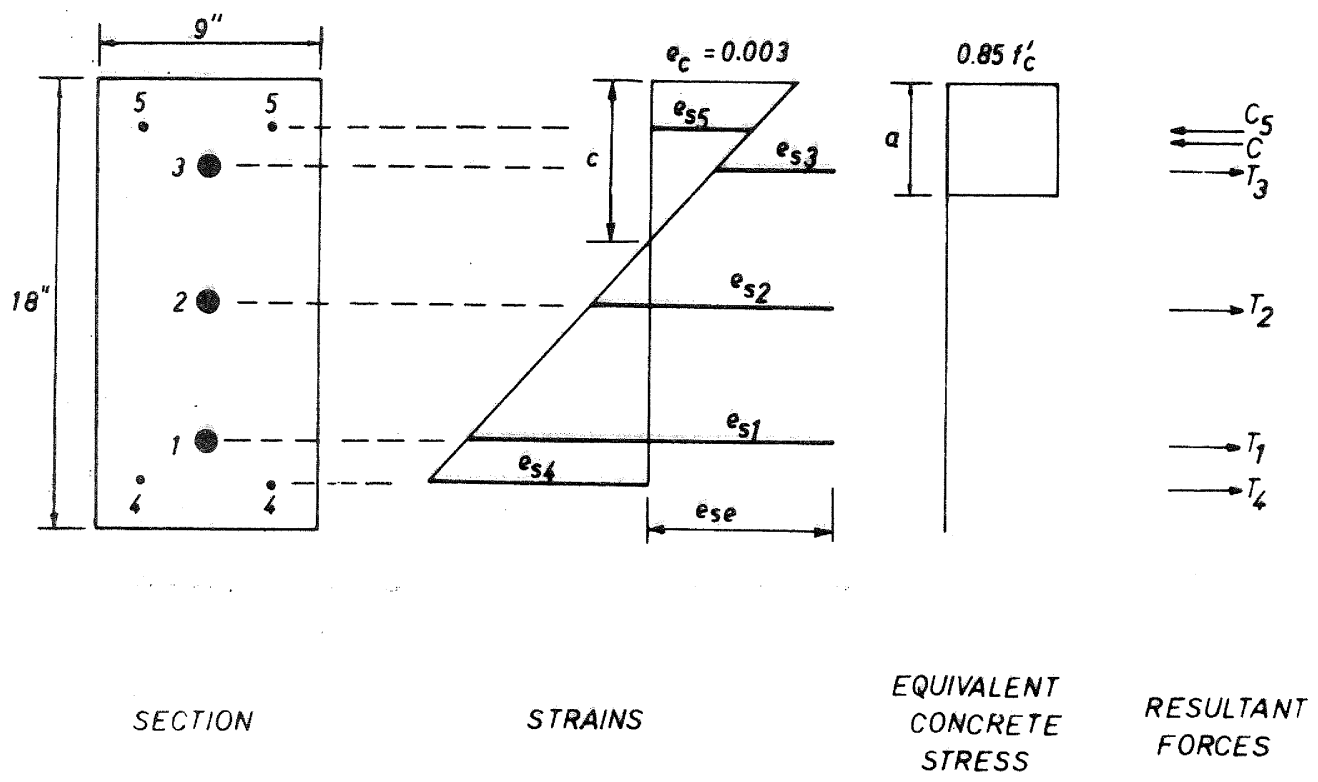

Fig. 17 Beam Section at the Flexural Strength.

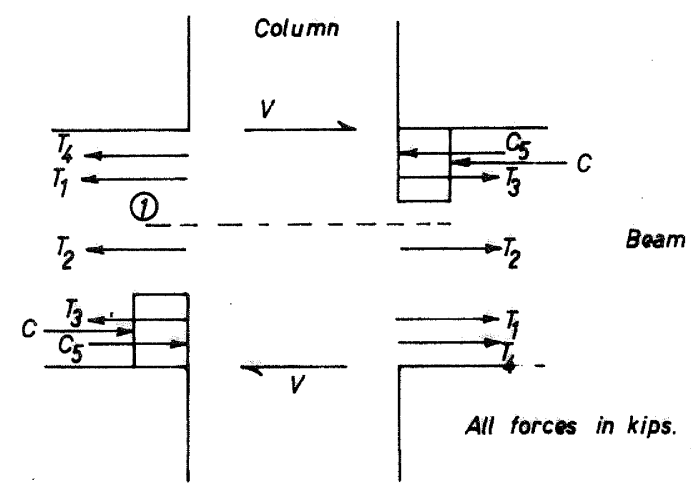

Fig. 18 Beam Forces Acting on Joint Core.

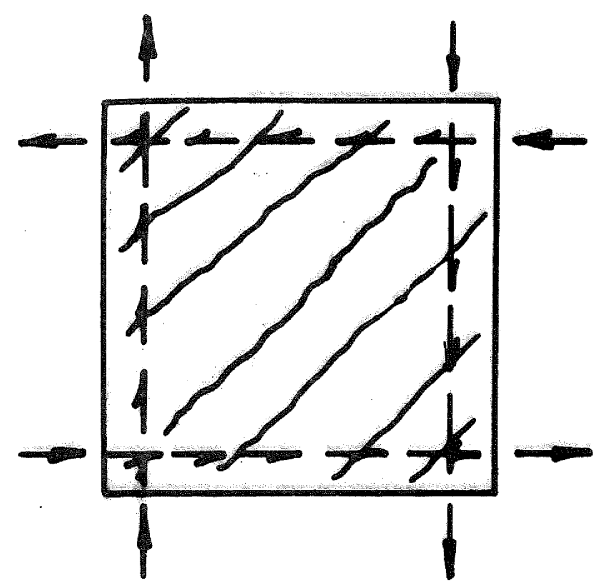

Steel bond forces only hoops required to transfer diagonal tension forces.

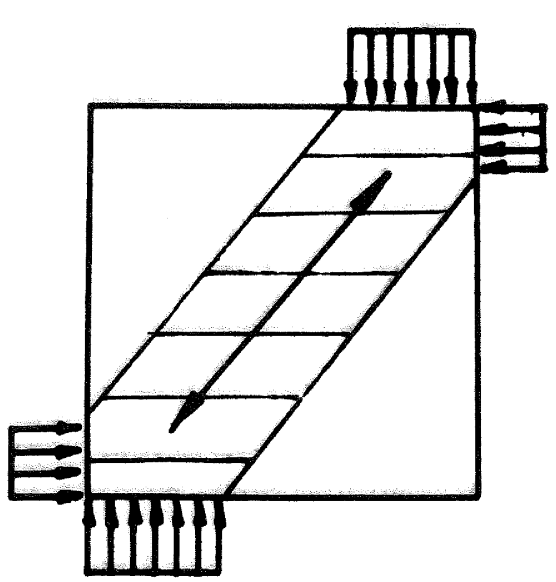

Concrete compression forces only nominal hoops required. 